\title{
A unified direct method for ratchet and fatigue analysis of structures subjected to arbitrary cyclic thermal-mechanical load histories
}

\author{
Zhiyuan $\mathrm{Ma}^{1}$, Xiaoxiao Wang ${ }^{1}$, Haofeng Chen ${ }^{1,2^{*}}$, Fu-Zhen Xuan ${ }^{2}$, Yinghua Liu ${ }^{3}$ \\ ${ }^{1}$ Department of Mechanical \& Aerospace Engineering, University of Strathclyde, James Weir \\ Building, 75 Montrose Street, Glasgow G1 1XJ, UK \\ ${ }^{2}$ Key Laboratory of Pressure Systems and Safety, Ministry of Education, East China University of \\ Science and Technology, Shanghai 200237, P.R. China \\ ${ }^{3}$ Department of Engineering Mechanics, Tsinghua University, Beijing 100084, P.R. China
}

\begin{abstract}
In this paper, the distinction between material ratchetting and structural ratchetting is clarified, and the concept of constant life diagram is extended to depict low cycle fatigue life boundary in structural design. To provide a novel one-stop solution for structural fatigue and ratchetting problems, a Unified Procedure for Fatigue and Ratchet Analysis (UPFRA) has been proposed. The UPFRA has been successfully applied to two different engineering structures considering complex geometry and temperature-dependent material properties. By comparing the results with ABAQUS step-by-step inelastic analysis, the UPFRA has been verified to be a robust engineering tool with great accuracy, usability, and efficiency.
\end{abstract}

Keywords: Ratchet; Low cycle fatigue; Direct methods; Linear Matching Method; Unified Procedure for Fatigue and Ratchet Analysis.

\section{Nomenclature}

Load ratio

V Body volume

$S \quad$ Body surface

$\theta \quad$ Thermal load

$P \quad$ Surface load

${ }^{*}$ Corresponding author: Haofeng Chen

Email: haofeng.chen@strath.ac.uk, Tel: +44(0)1415482036 


\begin{tabular}{|c|c|}
\hline$F$ & Total load \\
\hline$x$ & Location in body \\
\hline$t$ & Time \\
\hline$t_{n}$ & Time instants \\
\hline$\Delta t$ & Cycle time \\
\hline$\dot{u}$ & Displacement rate \\
\hline$\hat{\sigma}_{i j}^{\theta}$ & Linear thermal stress solution \\
\hline$\hat{\sigma}_{i j}^{P}$ & Linear mechanical stress solution \\
\hline$\hat{\sigma}_{i j}$ & Total linear stress solution \\
\hline$\sigma_{i j}$ & Steady-state stress \\
\hline$\hat{\sigma}_{i j}^{\bar{F}}$ & Constant part of stress \\
\hline$\hat{\sigma}_{i j}^{\Delta}$ & Cyclic part of stress \\
\hline $\bar{\rho}_{i j}$ & Constant residual stress field \\
\hline$\rho_{i j}^{r}$ & Varying residual stress field \\
\hline$\sigma_{i j}^{c}$ & Stress at yield \\
\hline$\dot{\varepsilon}_{i j}^{c}$ & Strain rate \\
\hline$\Delta \varepsilon_{i j}^{c}$ & Associated compatible strain increment \\
\hline$\sigma_{y}$ & Yield stress \\
\hline$\mu$ & Shear modulus \\
\hline$\Delta \varepsilon_{i j}^{P}$ & Plastic strain amplitude \\
\hline$\Delta \varepsilon_{P}$ & Platic strain range \\
\hline
\end{tabular}




\begin{tabular}{|c|c|}
\hline$\Delta \bar{\varepsilon}$ & Total strain range \\
\hline$N$ & Number of cycles to failure \\
\hline$\varepsilon_{R}$ & Effective ratchet strain \\
\hline$\lambda$ & Load multiplier \\
\hline$T$ & Temperature \\
\hline$\Delta T$ & Temperature difference \\
\hline$i$ & Iteration number \\
\hline LB & Lower bound \\
\hline UB & Upper bound \\
\hline FEA & Finite Element Analysis \\
\hline $\mathrm{HCF}$ & High cycle fatigue \\
\hline LCF & Low cycle fatigue \\
\hline EPP & Elastic Perfectly Plastic \\
\hline SBS & Step-by-Step \\
\hline CONV & Convergence parameter \\
\hline LMM & Linear Matching Method \\
\hline DSCA & Direct Steady Cycle Analysis \\
\hline UPFRA & Unified Procedure for Fatigue and Ratchet Analysis \\
\hline PEEQ & Equivalent plastic strain \\
\hline PEMAG & Plastic strain magnitude \\
\hline
\end{tabular}




\section{Introduction}

With the development of economy and technology, pressure vessels are becoming more complicated and large-scale than ever. They are widely used in heavy industries including petrochemical, non-ferrous metal and nuclear industries, and structural integrity assessment has become increasingly important due to the requirement of structural life assessment and life extension [1-3]. As part of the structural integrity assessment, fatigue and ratchetting have become traditional topics studied by many researchers [4-9]. Fatigue and ratchetting are both induced by cyclic loading. Fatigue leads to local crack initiation and propagation, but ratchetting induces global incremental collapse due to the accumulation of plastic deformation.

Ratchetting is often observed from material experiments with tension bars subjected to cyclic stresses where the stress range exceeds twice the yield stress [10]. However, for structural components, ratchetting can be found in any geometries when the cyclic load exceeds the structural ratchet limit. There are several other differences between material ratchetting and structural ratchetting. For material ratchetting, a homogeneous cyclic stress field is considered with no residual stress involved. It is typically activated by non-zero mean stress or zero mean stress with tensioncompression asymmetry [11]. A variable accumulation rate can be detected with the increasing number of cycles, so material ratchetting is commonly described by sophisticated constitutive models [12]. While for structural ratchetting, an inhomogeneous cyclic stress field is often considered with residual stress involved. A constant accumulation rate is presumed after a number of cycles. Structural ratchetting can be demonstrated by an Elastic Perfectly Plastic (EPP) model for conservatism and simplification during the safety check in engineering designs [13]. The structural ratchetting has been explained by a two-bar structure experiment $[14,15]$.

To evaluate structural ratchetting behaviour, Bree [16] have proposed the Bree diagram, which formed the basis of NB-3222.5 in ASME III [17]. The Bree problem is a simplified representation of a thin cylindrical vessel subjected to inner pressure and cyclic temperature gradient across the thickness direction. The Bree diagram has also been proposed, which indicates the structural 
behaviour and failure mechanism given any combination of the scaled thermal-mechanical loads. However, the Bree problem only considers constant membrane stress and cyclic bending stress. Thus the modified Bree problem $[18,19]$ has been introduced for arbitrary thermo-mechanical load histories. Many approaches have been proposed to solve the Bree-like problems for engineering structures, including the analytical approach [16, 18], incremental Finite Element Analysis (FEA), the Direct Cycle Analysis (DCA) [20-22], the Noncyclic Method [23, 24], and the direct methods [25-34]. Based on FEA simulation, the direct methods consider the static theorem by Melan [35] or the kinematic theorem by Koiter [36] and features high computational efficiency. The direct methods mainly contain mathematical programming methods [25-29] and several modified elastic modulus methods [30-34], including the Reduced Modulus Method [30], the Generalised Local Stress-Strain (GLOSS) Method [31, 37], the Elastic Compensation Method [32, 38], the stress compensation method (SCM) [39, 40], and the Linear Matching Method [19, 29, 33, 34, 41-43].

As another traditional topic in the field of industrial engineering, fatigue behaviour can be divided into two forms: high cycle fatigue (HCF) and low cycle fatigue (LCF) $[44,45]$. The high cycle fatigue occurs when the material remains in the elastic region; while the low cycle fatigue is often observed when plasticity is present, and the number of cycles to failure is lower than $5 \times 10^{4}$ [46]. The HCF life is evaluated using the stress-life (S-N) curves [47] of the material; while the LCF life can be calculated using the Coffin and Manson Law [48, 49] and the strain-life (E-N) curves. While performing fatigue designs, the constant life diagrams are often considered, which represent the safety region of constant amplitude cyclic loading for a specific fatigue life [50]. The constant life diagram is often depicted by plotting the alternating stress versus the mean stress [51]. From the material level, the concept can be further extended to depict LCF life boundary in structural design. In this work, a series of constant fatigue life curves have been derived for industrial components. The LCF life boundaries are plotted for different loading conditions with arbitrary thermal and mechanical loads, so the number of cycles to failure can be readily determined for given load combinations. 
The classical method for plastic strain range estimation is the Neuber's rule [52-54], which requires conducting a linear elastic analysis before a correction is made to predict the local plastic strain range at stress concentration regions. The Neuber's rule is widely employed in industries with advantages of safety and high efficiency. However, it heavily depends on local geometries and is only applicable to blunt notches [55]. It is often considered to be over-conservative for sharp notches [56]. Another approach for low cycle fatigue evaluation is the elastic-plastic method in ASME VIII-2 [57]. Based on the requirement of the nonlinear cycle-by-cycle FE analysis, the elastic-plastic method is highly precise but also computational consuming. Featuring great accuracy and time efficiency, the Direct Steady Cycle Analysis (DSCA) method [34, 58] has been proposed as part of the Linear Matching Method (LMM) framework. Based on a series of linear elastic equations, the DSCA subroutine can calculate the varying residual stress iteratively and compute the plastic strain range for any integration points in the FE model. The saturated hysteresis loop can then be plotted, and the structural low cycle fatigue damage can be evaluated.

This work aims to cover a few existing literature gaps. Firstly, the constant life diagrams have been mainly used for specific materials, but they have been rarely considered to describe structural behaviours and aid component design. Secondly, the evaluation of ratchet limit for modified Bree problems has been discussed in $[19,59]$, but few researchers have considered the computation of an LCF life boundary for multiple cyclic loads using direct methods, let alone a unified methodology for both ratchet and fatigue analyses. To provide a novel one-stop solution for structural fatigue and ratchetting problems, a Unified Procedure for Fatigue and Ratchet Analysis (UPFRA) has been developed for structures subjected to arbitrary thermo-mechanical load histories. By performing a series of DSCA analyses, the UPFRA can evaluate both the constant fatigue life curves and the ratchet limit using an iterative bisection scheme. The interaction diagram between two different cyclic loads can then be plotted by combining the shakedown boundary, the ratchet boundary and the LCF life boundary. Given a specific load combination, the minimum number of cycles to failure in the 
component can be directly determined from the LCF life boundary. The temperature-dependent material properties have also been considered for enhanced accuracy and viability.

The paper is structured as follows: a systemic introduction to the proposed numerical procedures for ratchet and fatigue analysis is first presented in Section 2, followed by two numerical examples to illustrate the proposed methodology in Section 3. Finally, some conclusions are given in Section 4.

\section{Numerical procedures for ratchet and fatigue analysis}

For typical Bree-like problems, the considered loading history is normally decomposed into cyclic and constant components. The Direct Steady Cycle Analysis (DSCA) [43, 60] algorithm and the Koiter's shakedown theorem [36] have been combined for the ratchet boundary evaluation. A data point on the ratchet boundary is calculated by fixing the cyclic load amplitude first and scaling the constant mechanical load to the ratchet limit. The cyclic load amplitude is then adjusted manually to plot a complete structural ratchet boundary.

For structural integrity assessment on components subjected to arbitrary thermal-mechanical load histories, the UPFRA has been recently developed to evaluate both the ratchet boundary and the LCF life boundary by iteratively performing a series of DSCA analysis. To plot the desired 2-D diagrams considering two cyclic loads, a load ratio $R$ between two loads is firstly chosen, before both loads are scaled proportionately until the ratchet limit or a specific structural lifetime is reached. By adjusting the load ratio $R$, several scale paths can be considered to plot a smooth curve.

\subsection{The Direct Steady Cycle Analysis (DSCA) algorithm}

Considering a body with volume $V$ and surface $S$ is subjected to cyclic temperatures $\theta(x, t)$ in $V$ and varying surface loads $P(x, t)$ on a section of the body surface $S_{T}$. At the remaining portion of the body surface $S_{U}$, the displacement rate $\dot{u}=0$. A typical time cycle $0 \leq t \leq \Delta t$ is considered here. The load history can then be disassembled into a cyclic thermal load and a cyclic surface load as follows: 


$$
F(x, t)=\theta(x, t)+P(x, t)
$$

where $\theta(x, t)$ and $P(x, t)$ denote the thermal and mechanical load histories within the time cycle $\Delta t$. The corresponding stress history is given by,

$$
\hat{\sigma}_{i j}(x, t)=\hat{\sigma}_{i j}^{\theta}(x, t)+\hat{\sigma}_{i j}^{P}(x, t)
$$

where $\hat{\sigma}_{i j}^{\theta}(x, t)$ and $\hat{\sigma}_{i j}^{P}(x, t)$ are the linear stress solution calculated with applied cyclic loads $\theta(x, t)$ and $P(x, t)$, respectively. The stress and strain rates of the predefined cyclic problem can reach a cyclic state after a few cycles:

$$
\sigma_{i j}(x, t)=\sigma_{i j}(x, t+\Delta t) \text { and } \dot{\varepsilon}_{i j}(x, t)=\dot{\varepsilon}_{i j}(x, t+\Delta t)
$$

The steady-state cyclic solution can then be decomposed into three parts:

$$
\sigma_{i j}(x, t)=\hat{\sigma}_{i j}(x, t)+\bar{\rho}_{i j}(x)+\rho_{i j}^{r}(x, t)
$$

where $\hat{\sigma}_{i j}(x, t)$ is the linear elastic solution. $\bar{\rho}_{i j}(x)$ is a constant residual stress field which satisfies zero surface traction on $S_{T} \cdot \rho_{i j}^{r}(x, t)$ denotes a varying residual stress field which satisfies $\rho_{i j}^{r}(x, 0)=$ $\rho_{i j}^{r}(x, \Delta t)=0$. For a convex yield condition, $f\left(\sigma_{i j}\right) \leq 0$. According to flow rule:

$$
\dot{\varepsilon}_{i j}^{p}=\dot{\alpha} \frac{\partial f}{\partial \sigma_{i j}}, \quad f=0
$$

where $\dot{\alpha}$ is a scalar plastic multiplier. According to maximum work principle:

$$
\left(\sigma_{i j}^{c}-\sigma_{i j}^{*}\right) \dot{\varepsilon}_{i j}^{c} \geq 0
$$

where $f\left(\sigma_{i j}^{c}\right)=0$ and $f\left(\sigma_{i j}^{*}\right) \leq 0 . \sigma_{i j}^{c}$ is the stress at yield and $\sigma_{i j}^{*}$ represents any stress state that satisfies the yield condition. Defining a function $I$ :

$$
I\left(\dot{\varepsilon}_{i j}^{c}\right)=\int_{V} \int_{0}^{\Delta t}\left\{\sigma_{i j}^{c} \dot{\varepsilon}_{i j}^{c}-\left(\hat{\sigma}_{i j}(x, t)+\rho_{i j}(t)\right) \dot{\varepsilon}_{i j}^{c}\right\} d t d V
$$

where $\dot{\varepsilon}_{i j}^{c}$ is kinematically admissible and $\rho_{i j}(t)=\bar{\rho}_{i j}+\rho_{i j}^{r}$. In DSCA, the integration of time is discretized into $N$ time instants, $t_{1}, t_{2}, t_{3}, \ldots, t_{N}$, where $t_{n}$ denotes a series of time instants in the cyclic history and the plastic strains are postulated to appear only at the vertices of the stress history $\hat{\sigma}_{i j}\left(t_{n}\right)$. The function $I$ can be discretized into individual functions $I^{n}$ :

$$
I\left(\dot{\varepsilon}_{i j}^{c}\right)=\sum_{n=1}^{N} I^{n}
$$


where

$$
\begin{gathered}
\Delta \varepsilon_{i j}^{c}=\sum_{n=1}^{N} \Delta \varepsilon_{i j}^{n} \\
I^{n}\left(\Delta \varepsilon_{i j}^{n}, \rho_{i j}\left(t_{n}\right)\right)=\int_{V}\left\{\sigma_{i j}^{n} \Delta \varepsilon_{i j}^{n}-\left(\hat{\sigma}_{i j}\left(t_{n}\right)+\rho_{i j}\left(t_{n}\right)\right) \Delta \varepsilon_{i j}^{n}\right\} d V \\
\rho_{i j}\left(t_{n}\right)=\bar{\rho}_{i j}+\sum_{l=1}^{n} \Delta \rho_{i j}^{l} \\
\Delta \varepsilon_{i j}^{T n}=C \Delta \rho_{i j}^{n}+\Delta \varepsilon_{i j}^{n}
\end{gathered}
$$

where $\Delta \rho_{i j}^{n}$ satisfies equilibrium and $\Delta \varepsilon_{i j}^{T n}$ is compatible. A minimization process of functions $I^{n}$ is then considered to achieve the minimization of function $I$. Assume $\Delta \varepsilon_{i j}^{n}=\Delta \varepsilon_{i j}^{n i}$, the shear modulus is defined as follows:

$$
\sigma_{y}=2 \bar{\mu}_{u i} \bar{\varepsilon}\left(\Delta \varepsilon_{i j}^{n i}\right)
$$

where $\sigma_{y}$ denotes the temperature-dependent or constant yield stress. A linear problem is given by,

$$
\begin{gathered}
\Delta \varepsilon_{i j}^{T f^{\prime}}=\frac{1}{2 \mu} \Delta \rho_{i j}^{n f^{\prime}}+\Delta \varepsilon_{i j}^{n f^{\prime}} \\
\Delta \varepsilon_{k k}^{T f}=\frac{1}{3 K} \Delta \rho_{k k}^{n f} \\
\Delta \varepsilon_{i j}^{n f^{\prime}}=\frac{1}{2 \bar{\mu}_{u i}}\left\{\hat{\sigma}_{i j}\left(t_{n}\right)+\rho_{i j}\left(t_{n-1}\right)+\Delta \rho_{i j}^{n f}\right\}^{\prime}
\end{gathered}
$$

where

$$
\rho_{i j}\left(t_{n-1}\right)=\rho_{i j}\left(t_{0}\right)+\Delta \rho_{i j}^{1}+\Delta \rho_{i j}^{2}+\Delta \rho_{i j}^{3}+\cdots+\Delta \rho_{i j}^{n-1}, \rho_{i j}\left(t_{0}\right)=\bar{\rho}_{i j}
$$

The linear problem is solved through a number of cycles with $n$ iterations in each cycle. The varying residual stress $\Delta \rho_{i j_{m}}^{n}$ is first calculated for the $n$th load instance at the $m$ th iteration cycle, where $n=1,2,3, \ldots, N$ and $m=1,2,3, \ldots, M$. The convergence condition $\sum_{n=1}^{N} \Delta \rho_{i j_{M}}^{n}=0$ should be satisfied at the $M$ th iteration cycle, where the constant residual stress can be calculated by,

$$
\bar{\rho}_{i j}=\sum_{n=1}^{N} \Delta \rho_{i j_{1}}^{n}+\sum_{n=1}^{N} \Delta \rho_{i j_{2}}^{n}+\sum_{n=1}^{N} \Delta \rho_{i j_{3}}^{n}+\cdots+\sum_{n=1}^{N} \Delta \rho_{i j_{M}}^{n}
$$

The plastic strain amplitude at time $t_{n}$ is then determined by,

$$
\Delta \varepsilon_{i j}^{P}\left(t_{n}\right)=\frac{1}{2 \bar{\mu}_{n}}\left(\hat{\sigma}_{i j}^{\prime}\left(t_{n}\right)+\rho_{i j}^{\prime}\left(t_{n}\right)\right)
$$

The equivalent ratchet strain indicating a net plastic strain increment over the cycle is given by, 


$$
\bar{\varepsilon}^{R}=\bar{\varepsilon}\left(\sum_{n=1}^{N} \Delta \varepsilon_{i j}^{P}\left(t_{n}\right)\right)
$$

The total strain range $\Delta \bar{\varepsilon}$ can also be evaluated by finding the maximum strain difference among all the time instants:

$$
\Delta \bar{\varepsilon}=\max \left(\bar{\varepsilon}\left(t_{a}\right)-\bar{\varepsilon}\left(t_{b}\right)\right), \quad \forall a \in[1, N], \forall b \in[1, N]
$$

\subsection{The evaluation of ratchet boundary for Bree-like problems}

A two-stage procedure has been proposed to calculate the ratchet boundary for Bree-like problems:

- Stage 1: evaluation of the varying residual stress field induced by a determined cyclic load using the DSCA algorithm.

- Stage 2: evaluation of the constant residual stress field and the ratchet limit multiplier using the Koiter's shakedown algorithm. The superposition of the linear elastic solution and the varying residual stress field from Stage 1 is used as the input.

The Koiter's upper bound theorem [36] is given by,

$$
\int_{0}^{\Delta t} \int_{V} \hat{\sigma}_{i j} \varepsilon_{i j}^{c} d t d V=\int_{0}^{\Delta t} \int_{V} \sigma_{i j}^{c} \varepsilon_{i j}^{c} d t d V
$$

where

$$
\hat{\sigma}_{i j}=\lambda \hat{\sigma}_{i j}^{\bar{F}}+\hat{\sigma}_{i j}^{\Delta}(x, t)+\rho_{i j}(x, t)
$$

where $\lambda$ is a load multiplier, $\hat{\sigma}_{i j}^{\bar{F}}$ is the constant stress, $\hat{\sigma}_{i j}^{\Delta}(x, t)$ is the cyclic stress, and $\rho_{i j}(x, t)$ is calculated from Eq. (11). Considering the discretization of time and the flow rule:

$$
\int_{0}^{\Delta t} \int_{V} \sigma_{i j}^{c} \varepsilon_{i j}^{c} d t d V=\int_{V} \sum_{n=1}^{N} \sigma_{i j}^{c^{n}} \Delta \varepsilon_{i j}^{n} d V=\int_{V} \sum_{n=1}^{N} \sigma_{y} \bar{\varepsilon}\left(\Delta \varepsilon_{i j}^{n}\right) d V
$$

where

$$
\bar{\varepsilon}\left(\Delta \varepsilon_{i j}^{n}\right)=\sqrt{\frac{2}{3} \Delta \varepsilon_{i j}^{n} \Delta \varepsilon_{i j}^{n}}
$$

The upper bound ratchet limit multiplier can then be evaluated by,

$$
\lambda=\frac{\int_{V} \sum_{n=1}^{N} \sigma_{y} \bar{\varepsilon}\left(\Delta \varepsilon_{i j}^{n}\right) d V-\int_{V} \sum_{n=1}^{N}\left(\widehat{\sigma}_{\mathrm{ij}}^{\Delta}\left(t_{n}\right)+\rho_{i j}\left(t_{n}\right)\right) \Delta \varepsilon_{i j}^{n} d V}{\int_{V} \widehat{\sigma}_{\mathrm{ij}}^{\bar{F}}\left(\sum_{n=1}^{N} \Delta \varepsilon_{i j}^{n}\right) d V}
$$


A series of linear problems are solved using the technique of modifying the elastic modulus, as described in [33]. Temperature-dependent yield stress can also be considered by replacing $\sigma_{y}$ with $\sigma_{y}(T)$

\subsection{The Unified Procedure for Fatigue and Ratchet Analysis (UPFRA)}

It is acknowledged the ratchet boundary and the constant fatigue life curves always lie in the region between the shakedown boundary and the limit load, so a three-stage procedure has been proposed for standardized and efficient fatigue or ratchet analyses:

- Stage 1: evaluation of the shakedown limit for a specific load ratio $R$.

- Stage 2: evaluation of the limit load of the structure.

- Stage 3: evaluation of the ratchet limit multiplier or the load multiplier required to reach a target low cycle fatigue life for a given load ratio $R$.

A simplified flowchart of the UPFRA has been presented in Fig. 1. The numerical procedures are written in the form of Python script and operate together with the DSCA subroutine. In the UPFRA, the inputs of load ratio $R$, convergence parameters $C O N V 1, C O N V 2, \lambda_{1}^{L B}$ and $\lambda_{1}^{U B}$ are required, where $\lambda_{1}^{L B}$ denotes the lower bound and $\lambda_{1}^{U B}$ denotes the upper bound multiplier. For the first iteration $i=$ $1, \lambda_{1}^{L B}$ is the shakedown limit multiplier calculated in Stage 1 , and $\lambda_{1}^{U B}$ is the limit load multiplier computed in Stage 2.

For fatigue analysis, a target number of cycles to failure $N_{T}$ is demanded. A bisection scheme is adopted to compute the load multipliers for better computational efficiency. At the first iteration, the trial load multiplier $\lambda_{1}=\left(\lambda_{1}^{L B 1}+\lambda_{1}^{U B 1}\right) / 2$. At the $i$ th iteration, the load multiplier for fatigue analysis $\lambda_{i}^{F}$ is calculated by,

$$
\begin{gathered}
\lambda_{i}^{L B 1}= \begin{cases}\lambda_{i-2}, & N_{i-2}>N_{T} \\
\lambda_{i-1}^{L B 1}, & N_{i-2} \leq N_{T}\end{cases} \\
\lambda_{i}^{U B 1}= \begin{cases}\lambda_{i-1}^{U B 1}, & N_{i-2}>N_{T} \\
\lambda_{i-2}, & N_{i-2} \leq N_{T}\end{cases}
\end{gathered}
$$




$$
\lambda_{i}^{F}= \begin{cases}\frac{\lambda_{i-1}+\lambda_{i}^{U B 1}}{2}, & N_{i-1}>N_{T} \\ \frac{\lambda_{i-1}+\lambda_{i}^{L B 1}}{2}, & N_{i-1} \leq N_{T}\end{cases}
$$

where $\lambda_{i}^{L B 1}$ is the lower bound load multiplier and $\lambda_{i}^{U B 1}$ is the upper bound load multiplier for fatigue analysis at the $i$ th iteration. Then the structural loads are scaled by $\lambda_{i}^{F}$ before calling the DSCA subroutine. Upon completion, the minimum number of cycles to failure $N_{i}$ in the structure is evaluated and compared with $N_{T}$ to check whether the convergence criterion is satisfied. If not, the scale factor is adjusted to repeat the process until the converged load multiplier is derived for a target fatigue lifetime.

For ratchet analysis, a target equivalent ratchet strain $\varepsilon_{T}^{R}$ is required. Due to possible numerical errors in FE analyses, the value of $\varepsilon_{T}^{R}$ is usually taken as $0.02 \%$ /cycle [19]. At the first iteration, the trial load multiplier $\lambda_{1}=\left(\lambda_{1}^{L B 2}+\lambda_{1}^{U B 2}\right) / 2$. At the $i$ th iteration, the load multiplier for ratchet analysis $\lambda_{i}^{R}$ is calculated by,

$$
\begin{gathered}
\lambda_{i}^{L B 2}= \begin{cases}\lambda_{i-2}, & \varepsilon_{i-2}^{R}<\varepsilon_{T}^{R} \\
\lambda_{i-1}^{L B 2}, & \varepsilon_{i-2}^{R} \geq \varepsilon_{T}^{R}\end{cases} \\
\lambda_{i}^{U B 2}= \begin{cases}\lambda_{i-1}^{U B 2}, & \varepsilon_{i-2}^{R}<\varepsilon_{T}^{R} \\
\lambda_{i-2}, & \varepsilon_{i-2}^{R} \geq \varepsilon_{T}^{R}\end{cases} \\
\lambda_{i}^{F}= \begin{cases}\frac{\lambda_{i-1}+\lambda_{i}^{U B 2}}{2}, & \varepsilon_{i-1}^{R}<\varepsilon_{T}^{R} \\
\frac{\lambda_{i-1}+\lambda_{i}^{L B 2}}{2}, & \varepsilon_{i-1}^{R} \geq \varepsilon_{T}^{R}\end{cases}
\end{gathered}
$$

where $\lambda_{i}^{L B 2}$ is the lower bound load multiplier and $\lambda_{i}^{U B 2}$ is the upper bound load multiplier for ratchet analysis at the $i$ th iteration. The other procedures are similar to the fatigue analysis, except that for ratchet analysis, the maximum equivalent ratchet strain $\varepsilon_{i}^{R}$ in the structure evaluated and compared to the target ratchet strain $\varepsilon_{T}^{R}$ for convergence checking. It is worth mentioning that the UPFRA script allows inputs of multiple load ratios $R$ so that they can be calculated successively to derive multiple data points on a ratchet boundary or an LCF life boundary. 


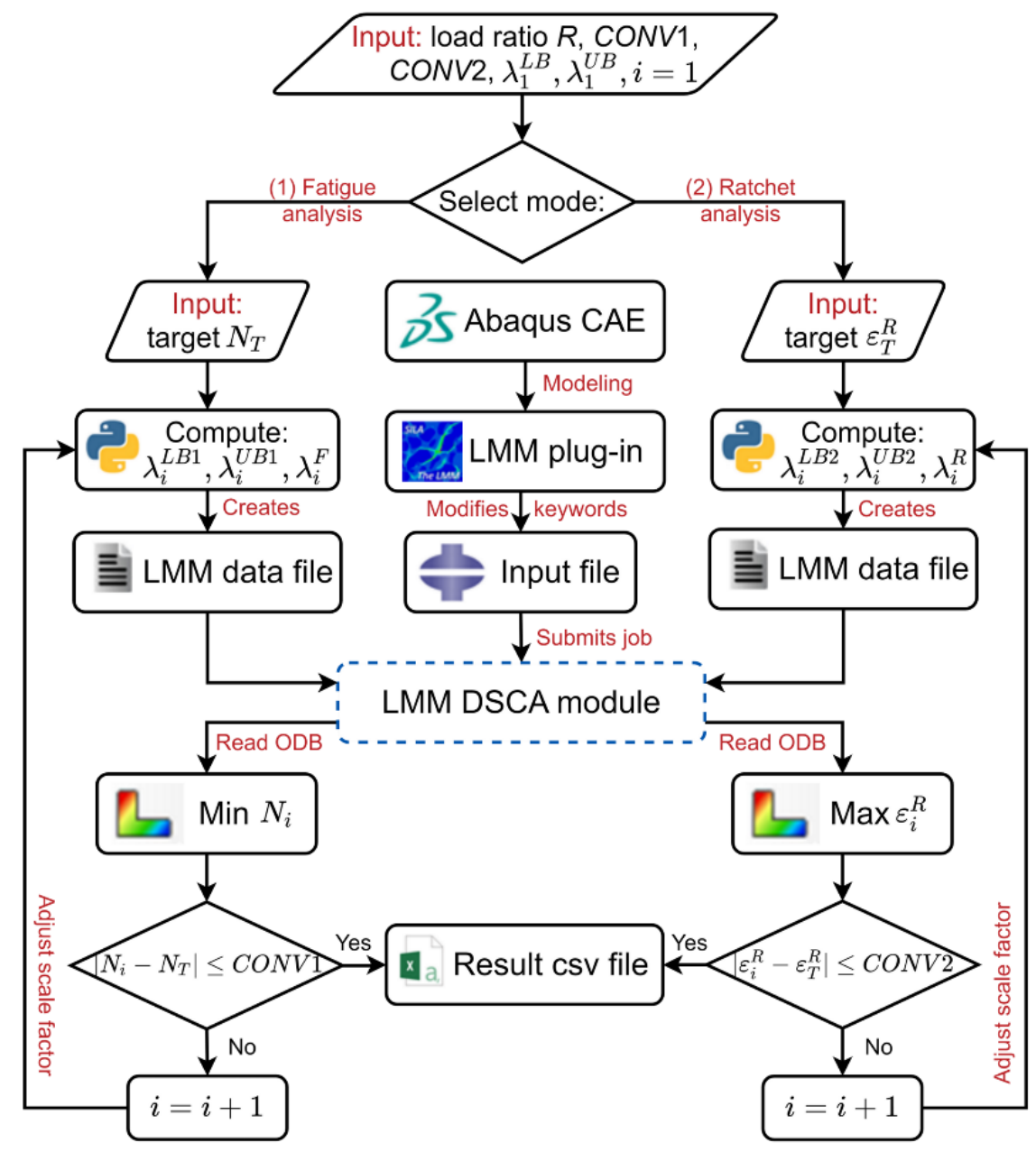

Fig. 1. Simplified flowchart of the Unified Procedure for Fatigue and Ratchet Analysis (UPFRA).

\section{Numerical examples}

\subsection{A heat exchanger in aero-engine}

In the field of aerospace engineering, a typical aero-engine is consists of a group of turbines to generate power for the aircraft. To ensure the normal function of the turbine system, it is essential to apply lubricating turbine oil to reduce friction between moving components. However, during the normal operating process, the turbine oil can be heated up due to friction and environment temperature. In this case, the viscosity and oxidation stability of the lubricating oil decreases with the increasing temperature, which significantly affects the performance of the lubricating oil [61]. Therefore, a shelland-tube heat exchanger is adopted in aero-engine to cool down the turbine oil, as shown in Fig. 2. 
Unlike typical thick, walled tubesheet design in [57], a thin, flexible tubesheet is welded to the head and shell parts of the heat exchanger.

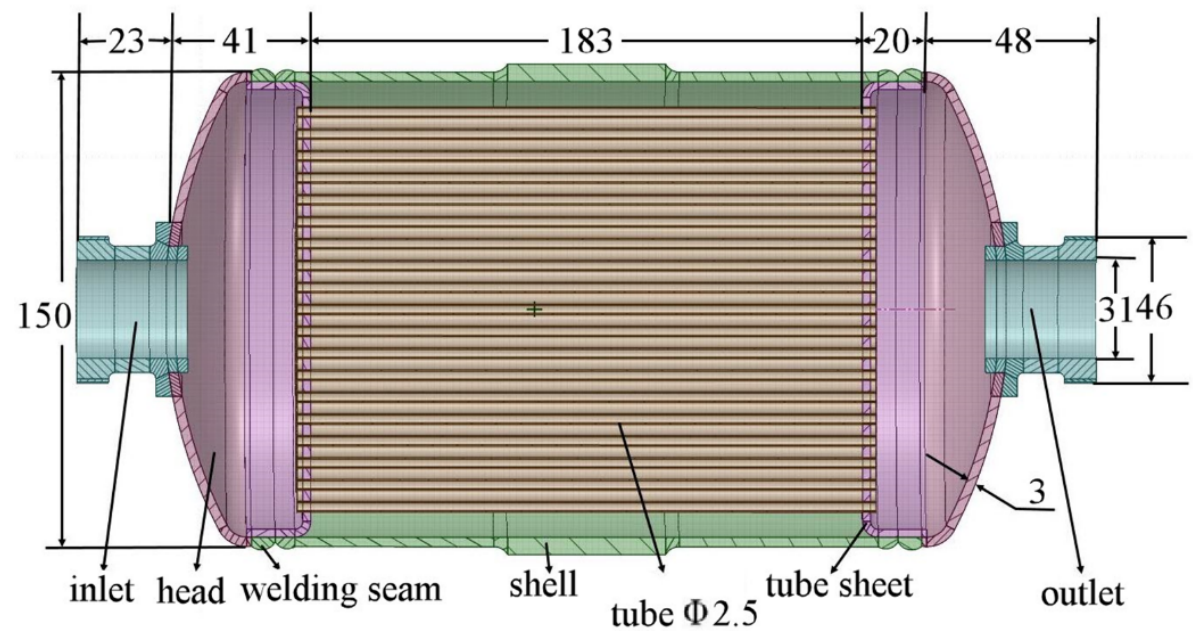

Fig. 2. The geometry of an assembled shell-and-tube heat exchanger (length in millimetres).

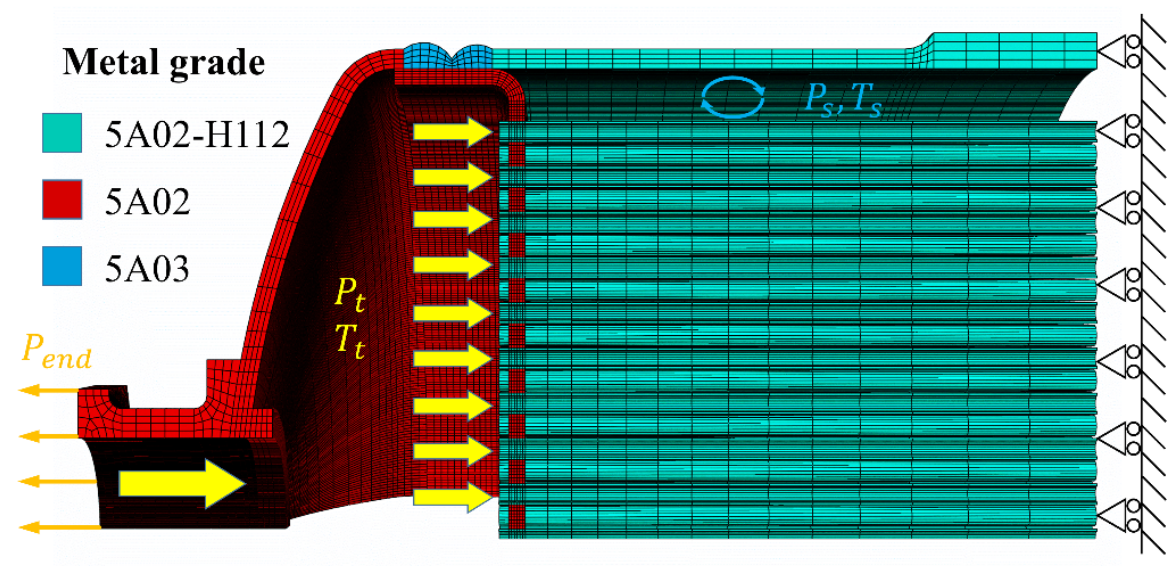

Fig. 3. The FE mesh, material designation and a typical operating condition.

To improve calculation efficiency, the heat exchanger has been simplified to a $1 / 8 \mathrm{FE}$ model, as shown in Fig. 3. It is worth mentioning that the traverse baffles in the heat exchanger shell have been neglected because they are not directly welded to the shell and have little effect on the structural loadbearing capacity. The model is then meshed into 245534 linear hexahedral elements of type C3D8 and 1968 linear wedge elements of type C3D6 in ABAQUS/CAE [62]. A refined mesh is applied to the tubesheet due to potential stress concentration. For a typical operating condition, the hightemperature turbine oil with pressure $P_{t}$ and temperature $T_{t}$ from the engine is transferred through the 
tubes of the heat exchanger, while coolant water is circulated inside the shell with pressure $P_{S}$ and temperature $T_{s}$. An equivalent pressure $P_{\text {end }}$ caused by the inner pressure is subjected to the end surface of the inlet. Symmetric boundary conditions have been applied on planes of symmetry to simulate the whole body and prevent rigid body movement. In addition, it can be found in Fig. 3 that the heat exchanger is built with three different materials, which are all aluminium but with varying grades of metal. The detailed material properties for each metal grade of aluminium is listed in Table 1. It should be mentioned that the material parameters used in this case are temperature-independent and material parameters at the highest temperature of the inlet turbine oil $\left(150^{\circ} \mathrm{C}\right)$ are chosen here due to the complexity of geometry and the consideration of conservatism. Using isothermal properties, in this case, leads to better convergence and less computation time considering the complicated geometry. The comparisons and justifications of using temperature-independent and temperaturedependent material parameters can be found in [43, 63].

Table 1 Material parameters for specified metal grades of aluminium at $150{ }^{\circ} \mathrm{C}$.

\begin{tabular}{cccc}
\hline Metal grade & 5A02-H112 & 5A02 & 5A03 \\
\hline Conductivity, $k\left[\mathrm{~W} /\left(\mathrm{m}^{\circ}{ }^{\circ} \mathrm{C}\right)\right]$ & 168 & 168 & 175 \\
Density, $\rho\left[\mathrm{g} / \mathrm{cm}^{3}\right]$ & 2.68 & 2.68 & 2.77 \\
Young's modulus, $E[\mathrm{GPa}]$ & 70 & 70 & 65 \\
Poisson's ratio, $v$ & 0.3 & 0.3 & 0.3 \\
Thermal expansion coefficient, $\alpha\left[10^{-5} /{ }^{\circ} \mathrm{C}\right]$ & 2.57 & 2.57 & 4 \\
Specific heat capacity, $c\left[\mathrm{~J} /\left(\mathrm{kg} \cdot{ }^{\circ} \mathrm{C}\right)\right]$ & 825 & 825 & 875 \\
Yield stress, $\sigma_{s}[\mathrm{MPa}]$ & 186 & 78 & 202 \\
\hline
\end{tabular}

Two simplified load cases have been considered and given in Fig. 4. Any creep effect and insignificant fluctuation during the operating process have been ignored. For ordinary working 
condition, the highest temperature of turbine oil $T_{t}=150{ }^{\circ} \mathrm{C}$; the pressure of turbine oil in the tube $P_{t}=3 \mathrm{MPa}$; the pressure of coolant water in the shell $P_{s}=1 \mathrm{MPa}$. In Fig. $4(\mathrm{a})$, the heat exchanger is subjected to constant tube/shell pressure and cyclic temperature; in Fig. 4(a), the heat exchanger is subjected to cyclic tube/shell pressure and cyclic temperature.
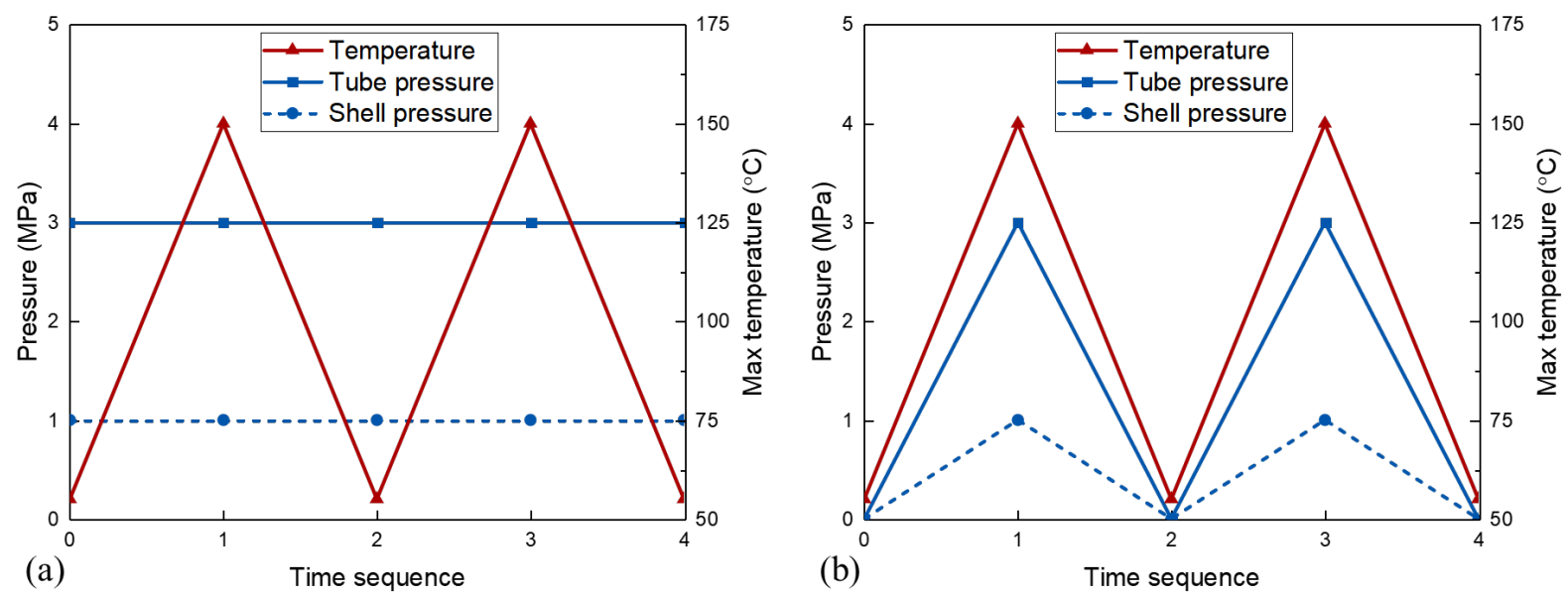

Fig. 4. Two simplified load cases: (a) constant inner pressure and cyclic temperature; (b) cyclic inner pressure and cyclic temperature.

The temperature field is generated based on a steady-state thermal analysis, as shown in Fig. 5(a). The inlet oil temperature is $150{ }^{\circ} \mathrm{C}$, and the coolant temperature in the shell is $55{ }^{\circ} \mathrm{C}$. A large temperature gradient can be observed in the tubesheet and the top end of tubes, which means a considerable thermal load would appear in this region. After applying the temperature field and the symmetric boundary conditions, an elastic analysis with pure thermal load is conducted. The most substantial temperature gradient is found on the tubesheet, so the equivalent von Mises stress at the tubesheet is presented in Fig. 5(c). For typical thick, walled tubesheet design, the thermal stress usually concentrates at the weldment between the tubesheet and shell. In this case, due to the nature of the flexible tubesheet, the thermal stress concentration can be observed at the transition corner of the tubesheet. By applying the inner pressure and boundary conditions, an elastic analysis with pure mechanical loads can be conducted, and the result is given in Fig. 5(b). The highest mechanical stress is found at the end of the head where the diameter is the largest and the wall is the thinnest in the whole heat exchanger. 

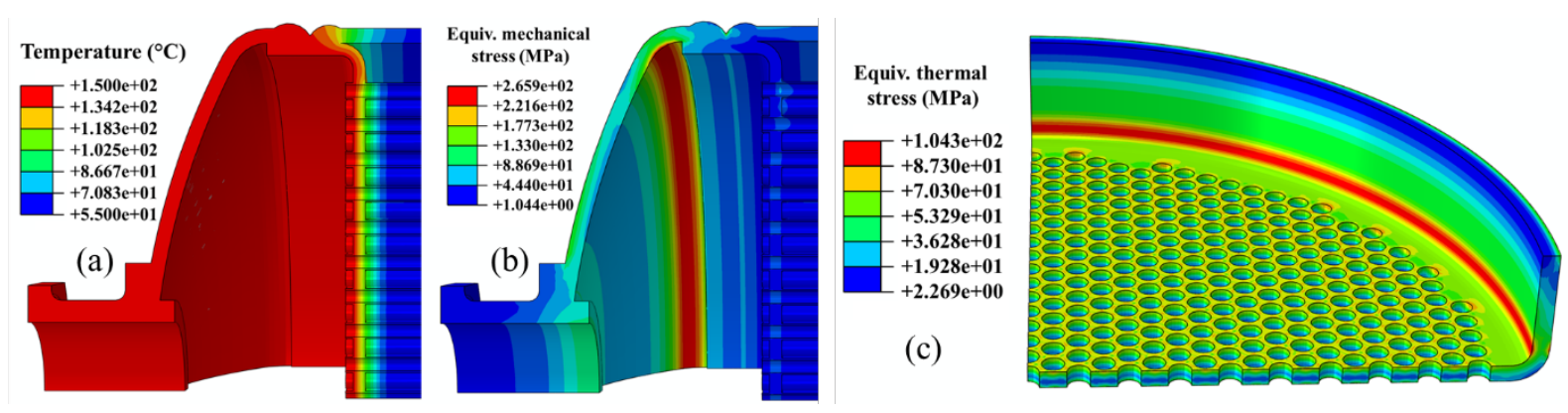

Fig. 5. Contours during loading stage: (a) the temperature distribution; (b) the mechanical von Mises stress; (c) thermal von Mises stress at the tubesheet.

Only the ratchet analysis has been performed for this example due to the structural design requirement. The shakedown, ratchet boundaries and the limit load of the heat exchanger subjected to constant mechanical load and cyclic thermal load has been presented in Fig. 6(a). For a typical Bree-like problem, the diagram is composed of a horizontal reverse plasticity limit on which the structural highest stress range equals twice the yield stress and an inclined ratchet limit that approaches the Y-axis. Hence the diagram is divided into several parts by the shakedown and ratchet boundaries: the structural response would be elastic/shakedown for all the load points within the shakedown limit; the structural response would be alternating plasticity leading to low cycle fatigue damage if the load points are outside the shakedown limit but within the ratchet limit; the structure would experience ratchetting and incremental collapse if the load points are outside the ratchet limit but lower than the limit load; for loads larger than the limit load, the structure would instantaneously collapse. It should be mentioned that both the inner pressure $P$ and temperature $\Delta T$ have been normalised by the limit load $P_{0}=2.939 \mathrm{MPa}$ and the reverse plasticity limit $\Delta T_{0}=229.2{ }^{\circ} \mathrm{C}$, respectively.

As mentioned in Section 2.2, the two-stage procedure is used for ratchet limit calculation. A load point on the ratchet boundary $(0.657,2.356)$ in Fig. $6(a)$ has been chosen for illustration. For this load point, the loading and unloading steady-state stress state contours by the end of stage I have been given in Fig. 7(a) and Fig. 7(b), respectively. Meanwhile the failure mechanism in the form of the 
equivalent strain increment $\Delta \varepsilon_{e q}^{c}$ by the end of stage II has been presented in Fig. 7(c). It can be observed that the critical location in the heat exchanger has shifted from the tubesheet during stage I to the head during stage II. The reason is that in stage I, only cyclic thermal load is considered, and the failure mechanism of alternating plasticity is dominated by the pure thermal load. While in stage II, the failure mechanism of ratchetting is dominated by the additional constant mechanical load.
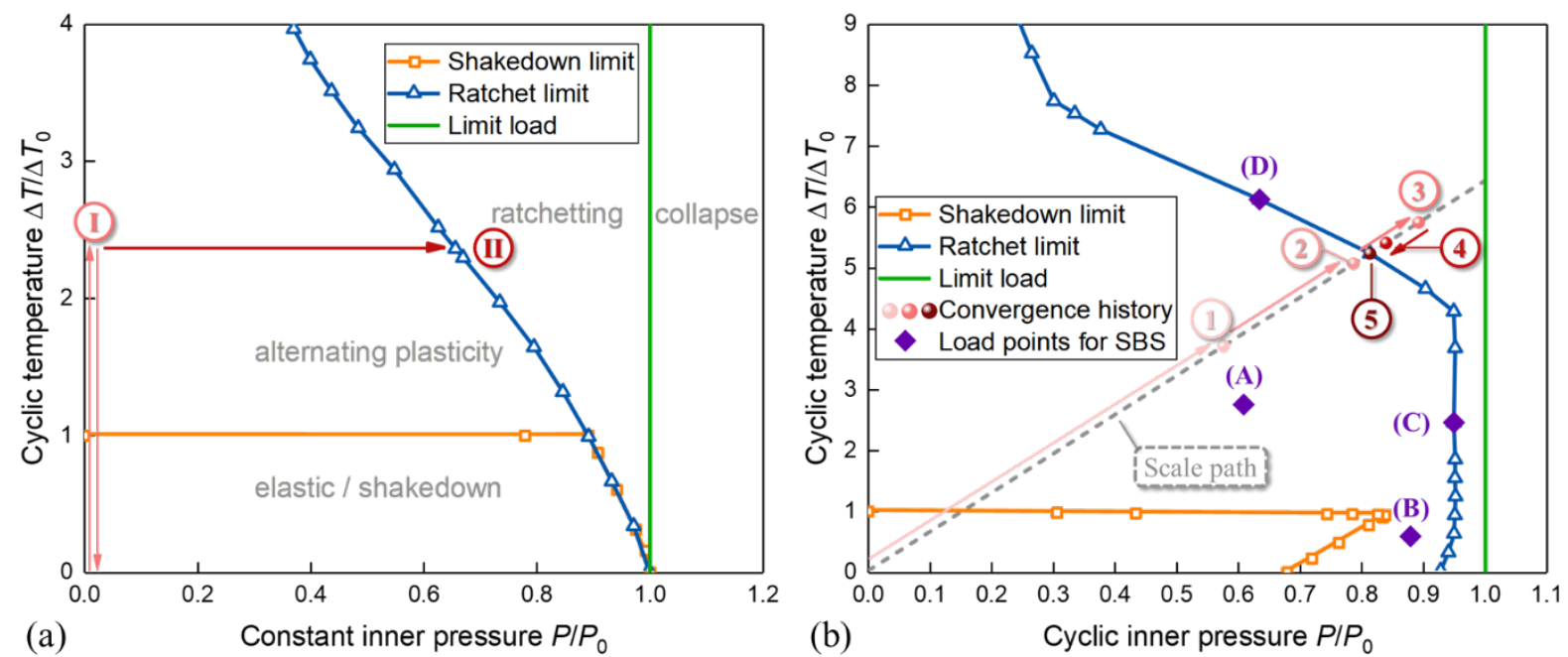

Fig. 6. Shakedown and ratchet limit of the aero-engine heat exchanger subjected to (a) constant mechanical load and cyclic thermal load; (b) cyclic mechanical load and cyclic thermal load.
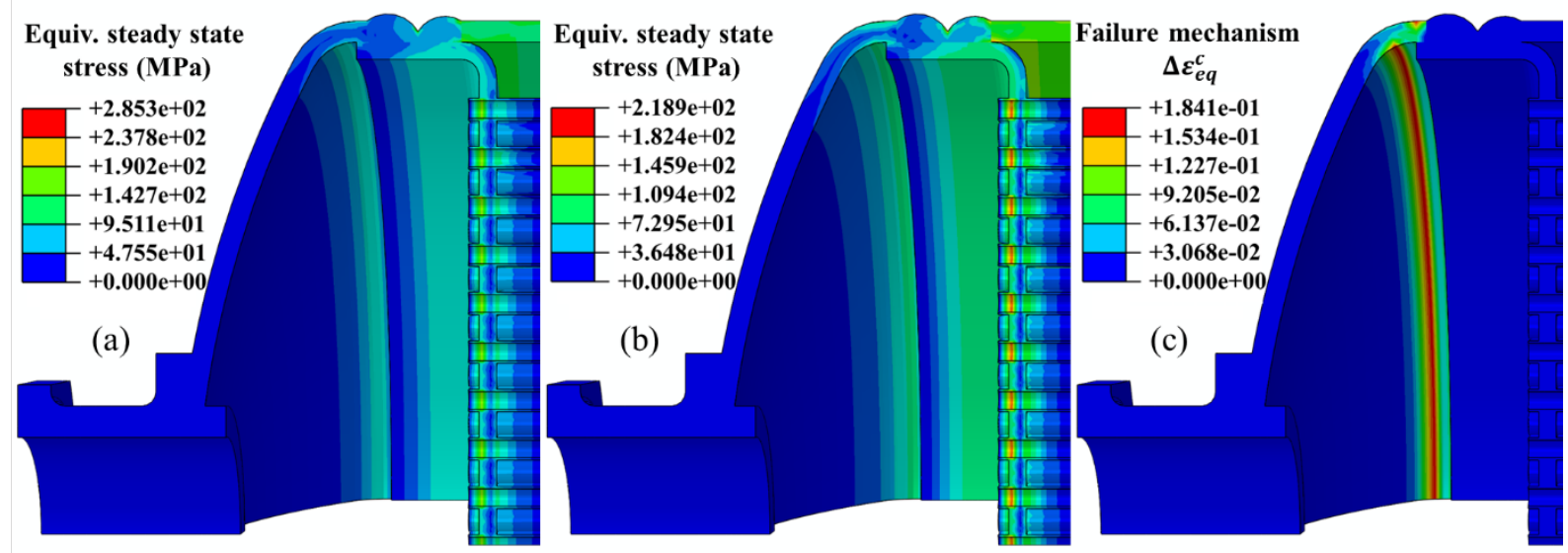

Fig. 7. Contours from the two-stage ratchet analysis: (a) von Mises steady-state stress for stage I during loading process; (b) von Mises steady-state stress for stage I during unloading process; (c) the failure mechanism for stage II. 
The structure behaviour and shakedown/ratchet boundaries would change significantly if the heat exchanger is subjected to cyclic mechanical load and cyclic thermal load, as shown in Fig. 6(b). Both the inner pressure $P$ and temperature $\Delta T$ have been normalised by the limit load $P_{0}$ and reverse plasticity limit $\Delta T_{0}$, respectively. Compared to the typical Bree-like diagram in Fig. 6(a), the limit loads are identical, as well as the reverse plasticity limit. However, the shakedown boundary intersects with $\mathrm{X}$-axis at 0.679 , instead of 1 in Fig. 6(a). The reason is that the stress state induced by the inner pressure is complex, containing both membrane and bending stress. The bending stress would cause the shrink of the shakedown boundary near the X-axis when the inner pressure becomes cyclic. Otherwise, if the mechanical load yields pure membrane stress in the structure, both the constant and cyclic mechanical load would result in the same shakedown limit. It can also be observed in Fig. 6(b) that with increasing ratio of $\Delta T / P$, the shakedown multiplier becomes larger, forming a sharp angle in the shakedown boundary. The reason is that the thermal and mechanical load interact with each other by counteracting stress in some regions of the structure. Thus, the shakedown boundary is maximised when the temperature and inner pressure level are comparable at load point $(0.838,0.940)$. In terms of the ratchet boundary, it is obtained using the UPFRA by setting the target maximum $\varepsilon_{R}=$ $0.02 \%$. The ratchet boundary is located between the shakedown boundary and the limit load, dividing the diagram into a reverse plasticity region and a ratchet region. The lower part of the ratchet boundary shares a similar trend as the shakedown boundary. Then a vertical part can be found in the ratchet boundary, which is parallel to the limit load. After that, the ratchet boundary rapidly shrinks and approaches the Y-axis gradually.

To determine the ratchet boundary, a series of scale paths with different ratio of $\Delta T / P$ have been considered, and both $\Delta T$ and $P$ have been scaled proportionally to reach the structural ratchet limit. An example scale path has been given in Fig. 6(b), showing the calculated ratchet limit at each subcycle along the specific scale path. A detailed convergence history of the load multiplier $\lambda$ has been shown in Fig. 8(a). For the first sub-cycle, using a typical bisection scheme, the middle point between the shakedown limit $\lambda_{s}=0.151$ and the limit load $\lambda_{L}=0.979$ is first found. It can be observed that 
the maximum ratchet strain yielded by the first sub-cycle $\lambda_{1}=0.565$ is smaller than the target ratchet strain, the middle point between the first sub-cycle and the limit load is thus chosen for the calculation of the second sub-cycle $\lambda_{2}=0.772$. By performing the bisection scheme repeatedly, the load multiplier $\lambda$ finally converged at the fifth sub-cycle where $\lambda_{5}=0.798$ and maximum structural $\varepsilon_{R_{5}}=$ $0.02 \%$.
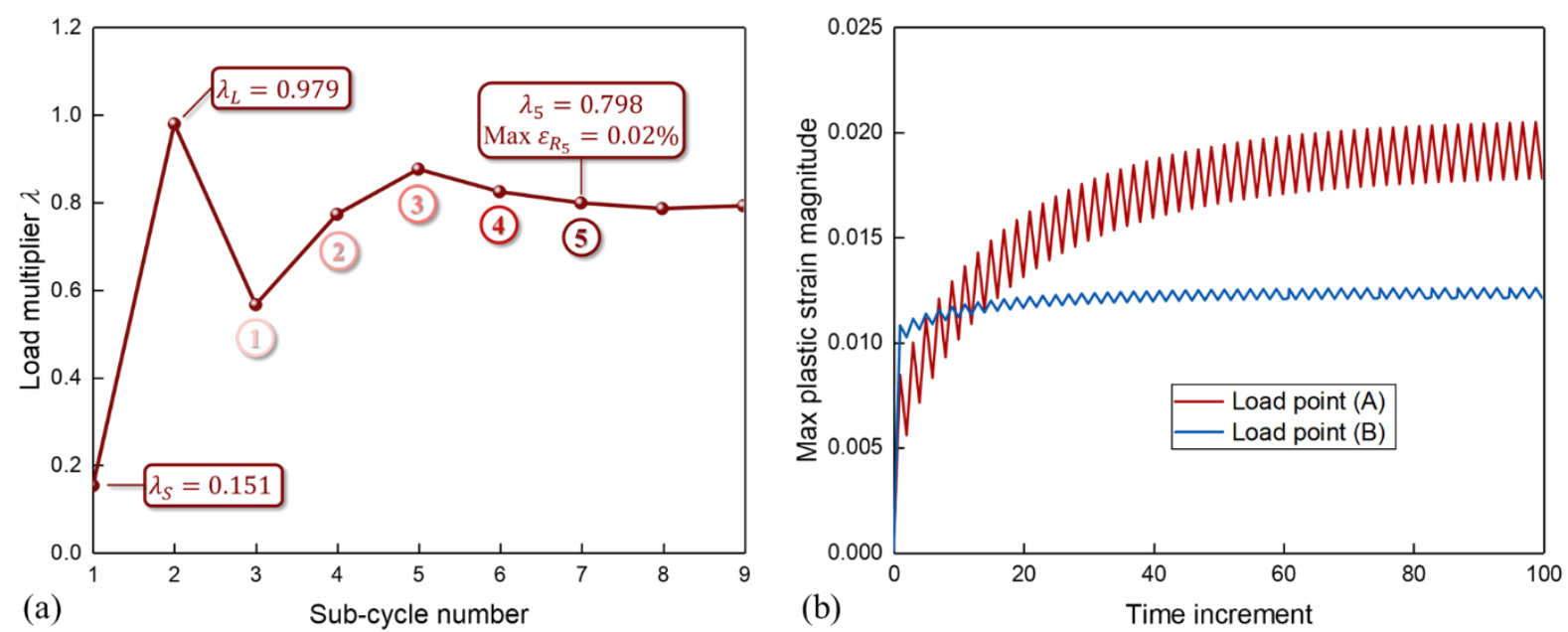

Fig. 8. (a) Convergence history of the load multiplier $\lambda$ for a specific scale path; (b) evolution of the maximum plastic strain magnitude of the aero-engine heat exchanger obtained with ABAQUS step-by-step analysis.

To verify the results, a series of ABAQUS step-by-step (SBS) has been conducted. A Python script has been developed to create a number of static steps in ABAQUS/CAE. The cyclic loading conditions are simulated by applying loads in turns for each step. For example, for load case (a), constant pressure and high temperature during the loading stage are applied at step number 1, 3, 5, etc. While constant pressure and low temperature during the unloading stage are applied at step number 2, 4, 6, etc. An EPP model is also specified in ABAQUS for inelastic calculation. The contours of the last few steps are checked when the calculation is completed to make sure steadystate behaviour is found in the structure. Many steps are usually required to reach saturated hysteresis loops and each step may take several increments to converge. Therefore SBS analyses are highly 
accurate but time-consuming. The technique of SBS verification has been widely used in some previous works $[64,65]$.

Four load points in Fig. 6(b) have been chosen for SBS verification. Both load point (A) and load point (B) are in the reverse plasticity region but with different $\Delta T / P$ ratio. A total of 100 recurring steps have been created for step-by-step (SBS) analysis, and an equivalent plastic strain range $\Delta \varepsilon_{P}$ is obtained by subtracting the equivalent plastic strain PEEQ at the step before the last step from the PEEQ at the last step. The evolution of the maximum plastic strain magnitude PEMAG of the aeroengine heat exchanger obtained with the SBS analysis for both load points has been given in Fig. 8(b). It can be seen that the maximum plastic strain magnitude gradually increases at the first few time increments before a steady-state level is reached. Thus, the structural behaviours for both load points are reverse plasticity, which proves the accuracy of the ratchet boundary calculated by the UPFRA. As shown in Fig. 9, the $\Delta \varepsilon_{P}$ obtained with the DSCA and the SBS analysis are highly comparable and similar. Dominated by the thermal load, the $\Delta \varepsilon_{P}$ at load point (A) concentrates at the tubesheet; dominated by the mechanical load, the maximum $\Delta \varepsilon_{P}$ at load point (B) occurs at the head of the heat exchanger. Therefore, different load points inside the ratchet boundary may have various critical locations for low cycle fatigue failure, depending on the dominance of thermal or mechanical loads. The comparisons between the DSCA and SBS have proven the precision and robustness of the DSCA. Also, as a direct method, the DSCA offers significantly better computational efficiency compared to the SBS without any difficulties in convergence. 

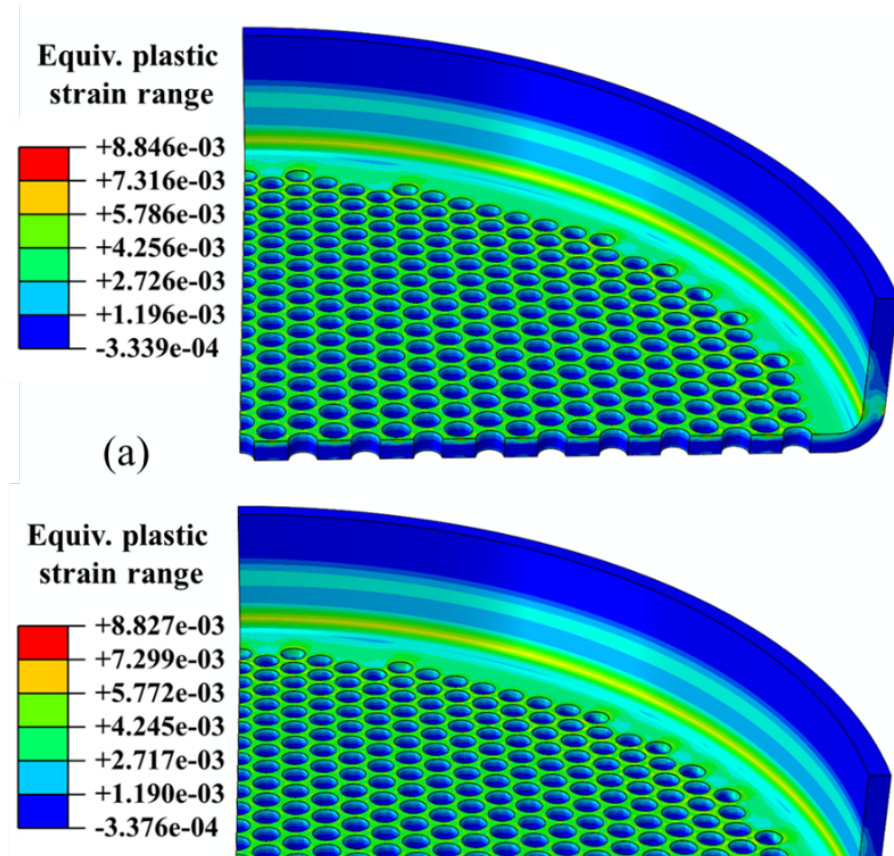

(b)

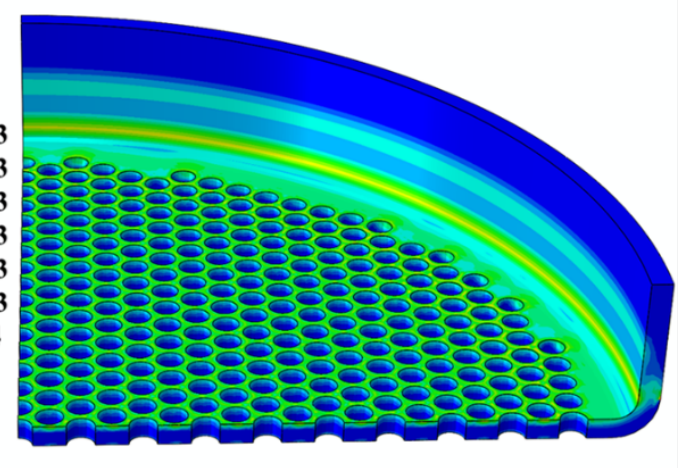

(c)

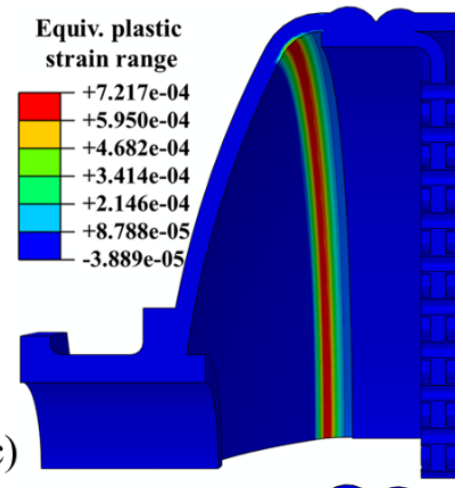

(d)

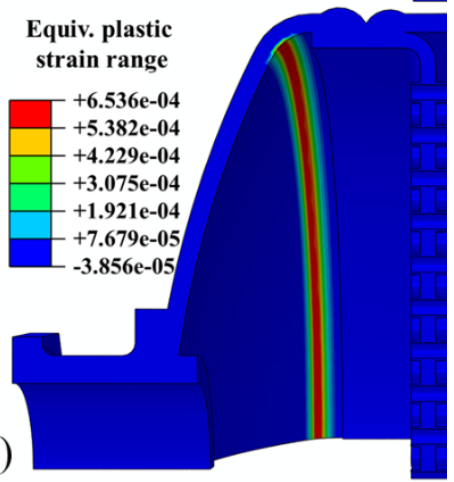

Fig. 9. Contours of the equivalent plastic strain range $\Delta \varepsilon_{P}$ for (a) load point (A) obtained with

DSCA; (b) load point (A) obtained with ABAQUS step-by-step analysis; (c) load point (B) obtained

with DSCA; (d) load point (B) obtained with ABAQUS step-by-step analysis.

(a)

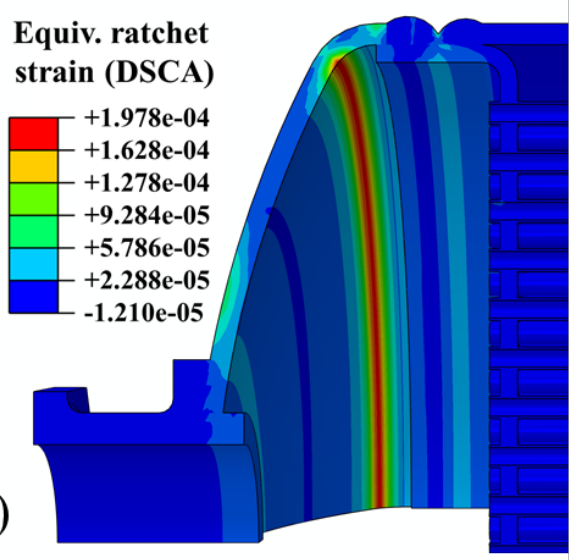

Equiv. ratchet strain (DSCA)

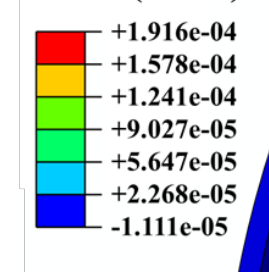

(c)

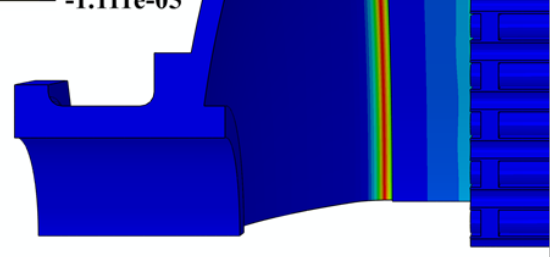

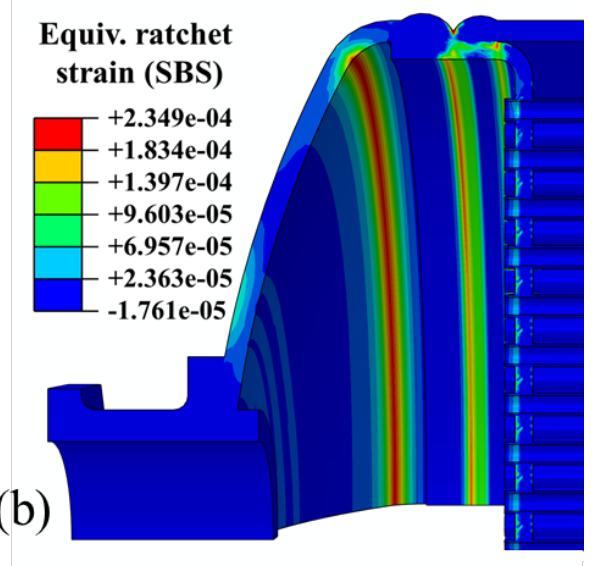

Equiv. ratchet strain (SBS)

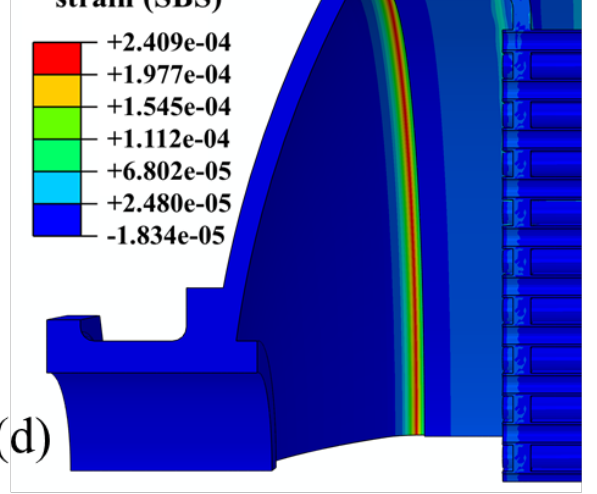


Fig. 10. Contours of the equivalent ratchet strain $\varepsilon_{R}$ for (a) load point (C) obtained with DSCA; (b) load point (C) obtained with ABAQUS step-by-step analysis; (c) load point (D) obtained with DSCA; (d) load point (D) obtained with ABAQUS step-by-step analysis.

Load points (C) and (D) have been further chosen in Fig. 6(b) for ABAQUS step-by-step (SBS) verification. Contours of the equivalent ratchet strain $\varepsilon_{R}$ obtained with DSCA and SBS have been plotted and compared in Fig. 10. The target $\varepsilon_{R}$ for this case is set to be $0.02 \%$. For load points located on the ratchet boundary, the largest $\varepsilon_{R}$ obtained with the DSCA is found to be nearly identical to the target value in Fig. 10(a) and Fig. 10(c). As shown in Fig. 10(b) and Fig. 10(d), the distribution and values of $\varepsilon_{R}$ obtained with SBS are highly similar compared to the ones obtained with DSCA. The minor difference is mainly caused by different procedures used during post-processing. For SBS, the $\varepsilon_{R}$ is calculated by subtracting the equivalent plastic strain accumulated during loading stage from the one accrued during unloading stage using the PEEQ values, while the $\varepsilon_{R}$ in DSCA is calculated by subtracting the plastic strain component during loading and unloading stage before computing the equivalent plastic strain. Despite the minor numerical variance, the high accuracy of the proposed approach has been proven for this case.

In terms of the efficiency of the proposed methodology, the comparisons of total CPU time for the computation of each load point using both DSCA and SBS have been given in Table 2. It can be observed that the overall CPU time using the DSCA is significantly less than the SBS, with a speed increase of up to $73.1 \%$. The reason is that the SBS analysis may require several increments in each step to converge when considering inelastic behaviour of the material, while the DSCA uses a series of linear elastic equations and aims for the steady-state structural behaviour at each iteration. To determine a load point on the ratchet boundary, a number of DSCA analyses are performed iteratively in the UPFRA, using the SBS for this objective would be much more time-consuming. Therefore, the high efficiency of the DSCA and UPFRA has been successfully proven. 
Table 2 Comparisons of total CPU time using the DSCA and SBS.

\begin{tabular}{|c|c|c|c|c|}
\hline & $\begin{array}{c}\text { Load point } \\
(\mathrm{A})\end{array}$ & $\begin{array}{c}\text { Load point } \\
(\mathrm{B})\end{array}$ & $\begin{array}{c}\text { Load point } \\
(\mathrm{C})\end{array}$ & $\begin{array}{c}\text { Load point } \\
(\mathrm{D})\end{array}$ \\
\hline CPU time (SBS) [sec] & 45711 & 40672 & 62136 & 76529 \\
\hline CPU time (DSCA) [sec] & 20426 & 20358 & 20404 & 20602 \\
\hline Speed improvement & $55.3 \%$ & $49.9 \%$ & $67.2 \%$ & $73.1 \%$ \\
\hline
\end{tabular}

\subsection{A holed plate}

As a classical geometry for shakedown and ratchet analysis, the holed plate is often considered as a simplified model to simulate a complete tubesheet in a typical heat exchanger [40]. As shown in Fig. 11(a), the holed plate is subjected to an axial pressure $\sigma_{P}$ and a thermal load caused by temperature difference $\Delta T=T-T_{0}$. The geometry sizes of the hold plate are identical to [19], with $D / L=0.2$ and $d / L=0.05$. To further simplify the problem, a quarter model is adopted in ABAQUS using symmetry boundary conditions. Then model is then meshed into 642 quadratic hexahedral elements of type C3D20R, as shown in Fig. 11(b). After that a steady-state thermal analysis has been conducted to calculate the temperature distribution in the model.
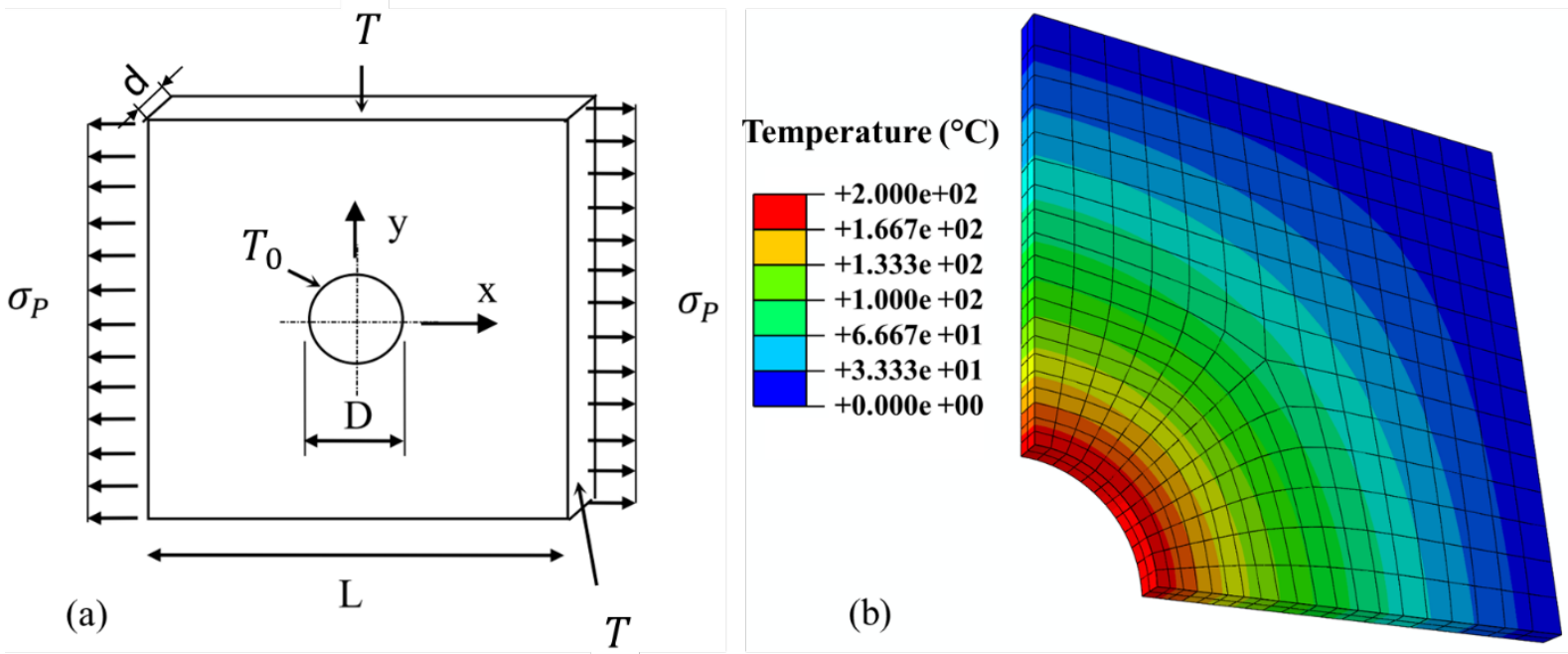

Fig. 11. (a) The geometry of a holed plate [19]; (b) the temperature distribution and FE mesh. 
Based on a previous work [19], the shakedown and ratchet analysis has been done for the same structure undergoing arbitrary thermo-mechanical load histories, with further consideration of temperature-dependent material properties. The material used in this case is X2CrNiMo17-12-2 steel, and its material parameters have been given in Table 3. It should be mentioned that linear interpolation and extrapolation techniques have been adopted to calculate the material properties for the scaled local temperature on each integration point. No hardening effect has been considered in this example for the sake of simplicity. All the temperature-dependent material properties are obtained from [43].

For the fatigue analysis, the fatigue life curves of $\mathrm{X} 2 \mathrm{CrNiMo17-12-2} \mathrm{steel} \mathrm{at} \mathrm{various} \mathrm{temperatures}$ have been shown in Fig. 12. The low-cycle fatigue life is calculated using a bilinear interpolation technique considering both the total strain range $\Delta \varepsilon_{t}$ and temperature $T$ on each integration points as input variables. The lowest fatigue life in the whole structure can then be derived as an output variable.

Table 3 Temperature-dependent material parameters of X2CrNiMo17-12-2 steel [43].

\begin{tabular}{cccccc}
\hline $\begin{array}{c}\text { Temperature, } \\
T\left[{ }^{\circ} \mathrm{C}\right]\end{array}$ & $\begin{array}{c}\text { Heat capacity, } \\
C_{p}(T) \\
{\left[\mathrm{J} /\left(\mathrm{kg}^{\left.\cdot{ }^{\circ} \mathrm{C}\right)}\right)\right.}\end{array}$ & $\begin{array}{c}\text { Conductivity, } \\
\lambda(T) \\
{\left[\mathrm{W} /\left(\mathrm{m}^{\circ} \mathrm{C}\right)\right]}\end{array}$ & $\begin{array}{c}\text { Thermal } \\
\text { expansion, } \\
\alpha(T)\left[10^{-5} /{ }^{\circ} \mathrm{C}\right]\end{array}$ & $\begin{array}{c}R_{p 0.2}(T) \\
{[\mathrm{MPa}]}\end{array}$ & $\begin{array}{c}\bar{E} \\
{[\mathrm{MPa}]}\end{array}$ \\
\hline 20 & 472 & 14.28 & 1.53 & 258 & \\
100 & 501 & 15.48 & 1.59 & 252 & \\
200 & 522 & 16.98 & 1.66 & 248 & $2.17 \times 10^{5}$ \\
300 & 538 & 18.49 & 1.72 & 240 & \\
400 & 556 & 19.99 & 1.78 & 240 & \\
\hline
\end{tabular}




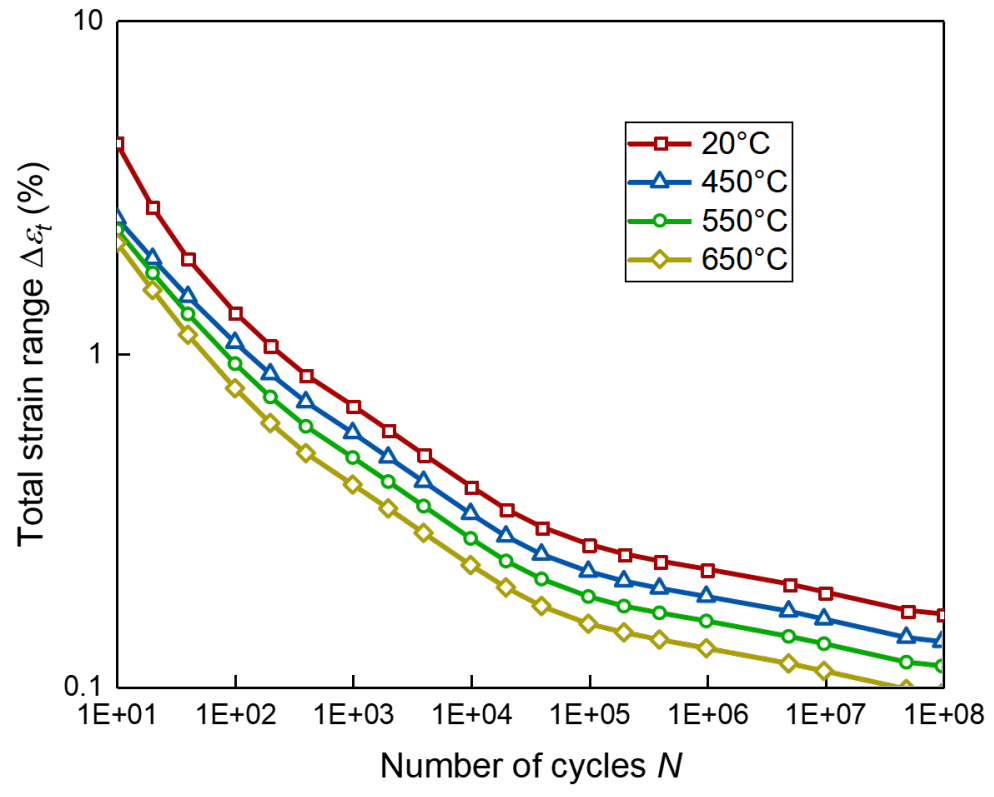

Fig. 12. Fatigue curves of X2CrNiMo17-12-2 steel at various temperatures [66].

Two simplified load cases have been studied in this work, as shown in Fig. 13. Load case I represents a cyclic axial load and a cyclic thermal load. The corresponding loading domain I is comprised of two load vertices: $(P, \Delta T)$ and $(0,0)$. While for load case II, the component is subjected to a constant axial load and a cyclic thermal load. The corresponding loading domain II consists of two load vertices: $(P, \Delta T)$ and $(P, 0)$.

A limit load analysis and a reverse plasticity limit analysis have been conducted using the LMM shakedown module. As a result, the limit load $P_{0}=225.5 \mathrm{MPa}$ and the reverse plasticity limit $\Delta T_{0}=$ $200{ }^{\circ} \mathrm{C} . P_{0}$ and $\Delta T_{0}$ are then used as the reference loads for future analyses. The elastic analysis contours of the component subjected to pure mechanical load $P_{0}$ and pure thermal load $\Delta T_{0}$ are presented in Fig. 14, respectively. It can be observed that both thermal and mechanical loads induce stress concentration around the inner hole of the square plate. 

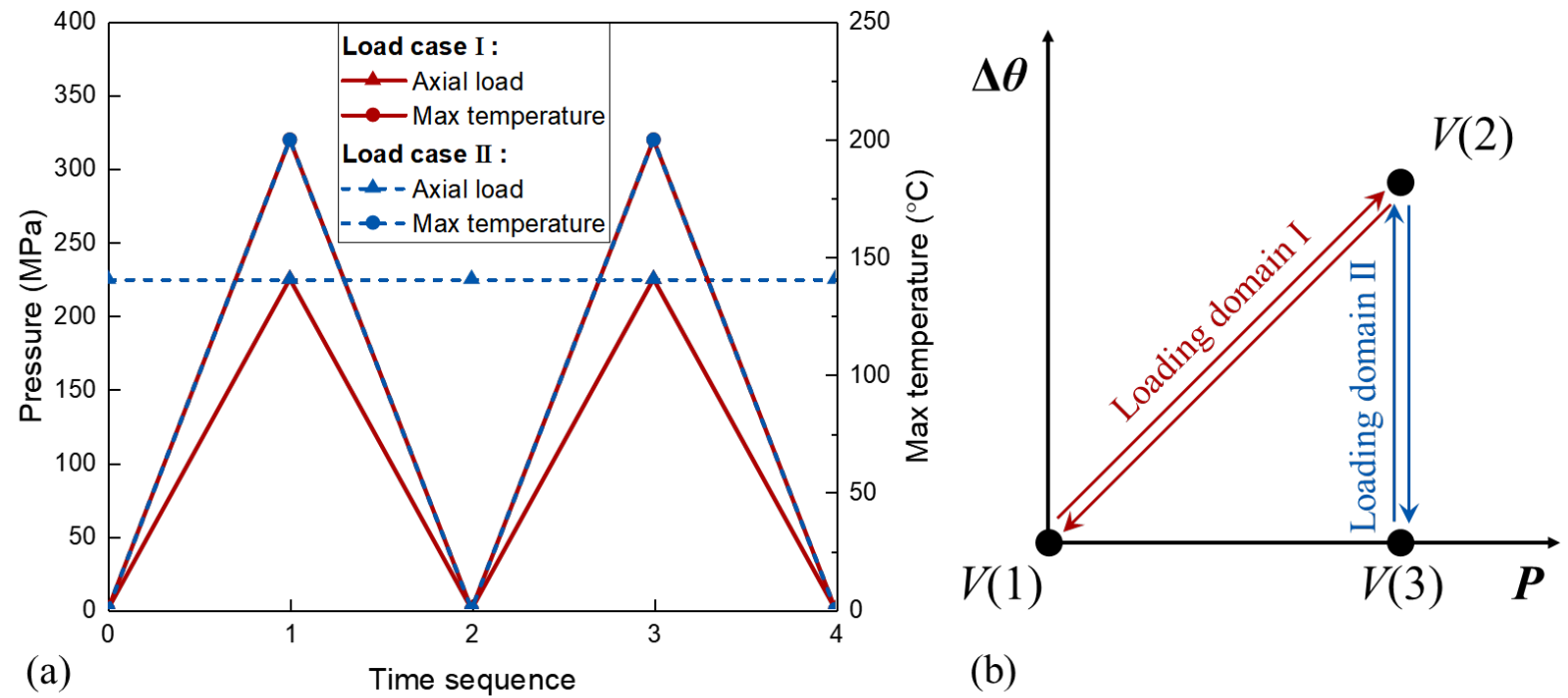

(a)

(b)

Fig. 13. (a) Two simplified load cases; (b) the corresponding loading domains.
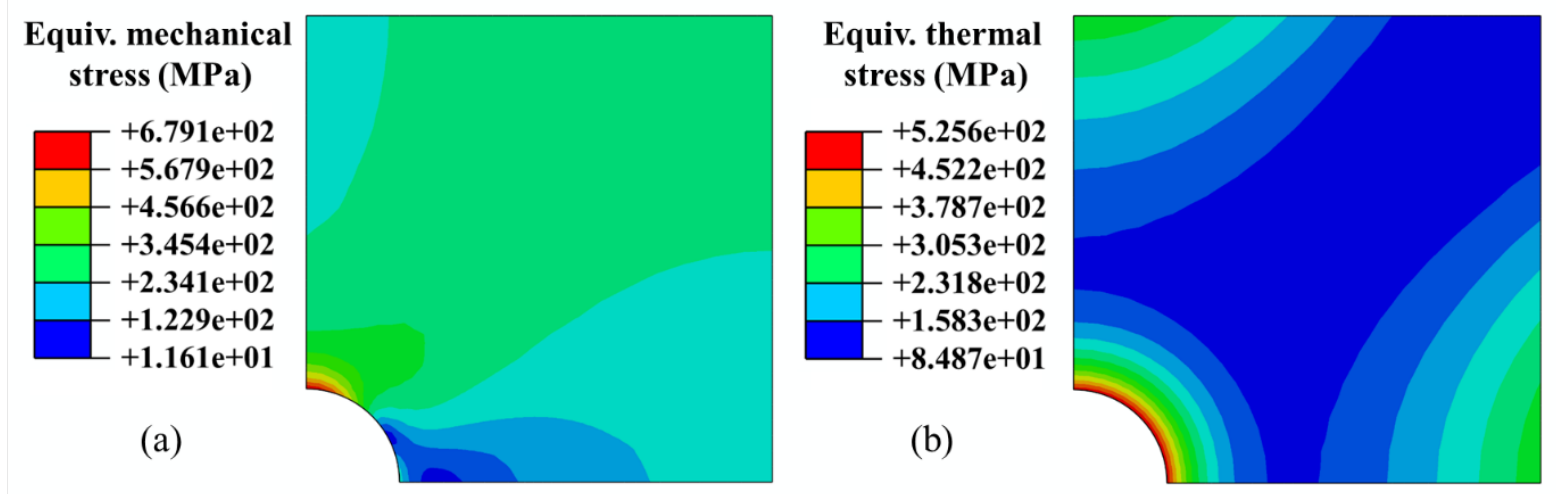

Fig. 14. Elastic analysis contours of (a) the mechanical von Mises stress; (b) the thermal von Mises stress during the loading stage.

The shakedown limit, ratchet limit and constant fatigue life curves of the holed plate subjected to load case I have been computed and presented in Fig. 15(a). Both the axial load $P$ and the temperature difference $\Delta T$ have been normalised by the reference loads $P_{0}$ and $\Delta T_{0}$, respectively. For load points located between the shakedown and ratchet limit, a closed hysteresis loop would form, and the structure would experience reverse plasticity leading to low cycle fatigue damage. A series of LCF life boundaries have been plotted, on which the low cycle fatigue life is constant for every load point on each constant fatigue life curve. It can be beneficial for designers to determine the fatigue life quickly for a structure subjected to arbitrary load combinations using the LCF life boundary. It can 
be observed that the constant fatigue life curves are nearly parallel to the reverse plasticity limit, which is part of the shakedown boundary. The constant fatigue life curves closer to the shakedown boundary represents a longer low cycle fatigue life. The shakedown boundary is comprised of the reverse plasticity limit and a part of the ratchet limit. The ratchet boundary shares its lower part with the shakedown boundary and approaches $\mathrm{Y}$-axis with increasing temperature difference $\Delta T$. It is worth noting that the lower part of the ratchet boundary is not vertical, like the one in [19]. The reason is that the temperature-dependent yield stress becomes lower with increasing temperature, leading to a slight shrink of ratchet boundary.

The shakedown limit, ratchet limit and constant fatigue life curves of the holed plate subjected to load case II has also been calculated and presented in Fig. 15(b). As a typical Bree-like problem with a constant mechanical load and a cyclic thermal load, the shakedown boundary consists of a horizontal reverse plasticity limit and part of the ratchet limit. The constant fatigue life curves are also horizontal and parallel to the reverse plasticity limit. It should be mentioned that all the shakedown limit, ratchet limit and constant fatigue life curves for both load cases are based on temperature-dependent material properties, making them more accurate and viable for use in industries.

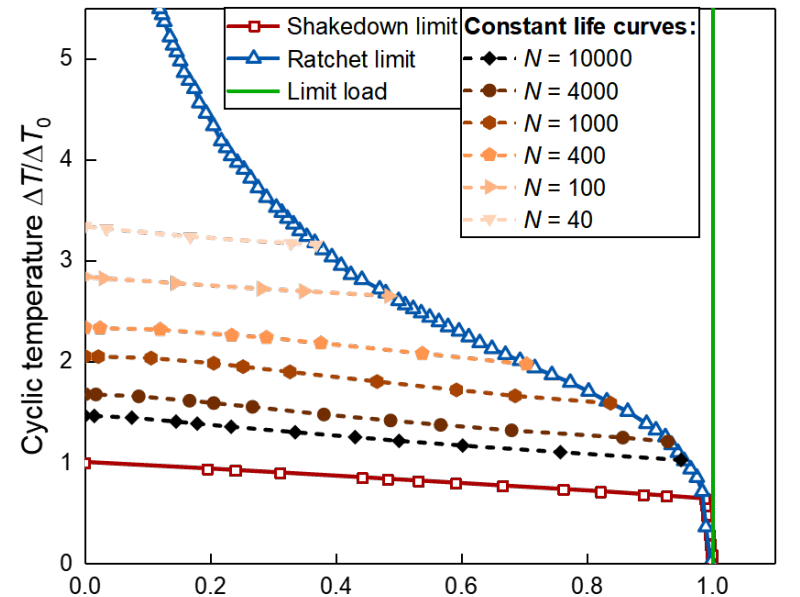

(a)

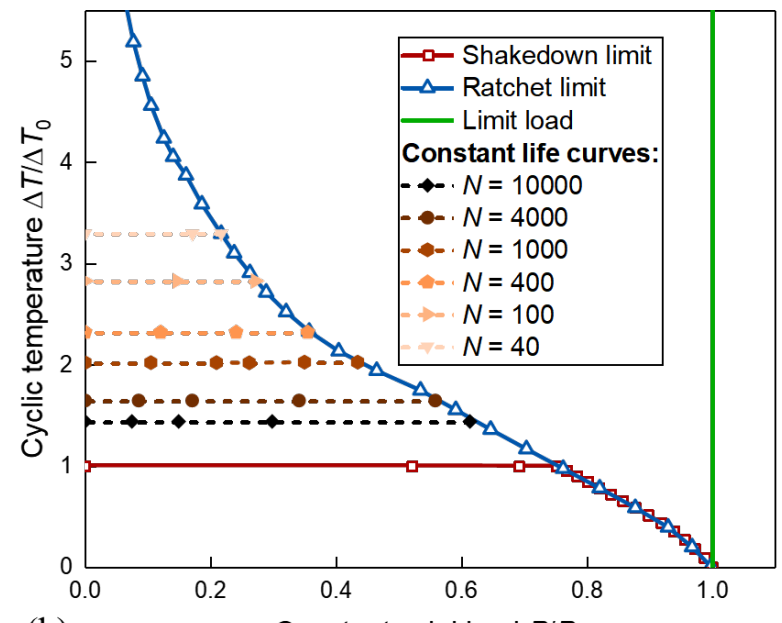

(b)

Constant axial load $P / P_{0}$

Fig. 15. Shakedown limit, ratchet limit and constant fatigue life curves of the holed plate subjected to (a) load case I; (b) load case II. 
Like the previous example, three scale paths for the evaluation of fatigue and ratchet diagram of the holed plate subjected to load case I have been shown in Fig. 16(a). In the UPFRA, a scale path specifies a certain ratio between the thermal and mechanical load and converges to a certain load point when the target parameter is reached. For ratchet analysis, the target equivalent ratchet strain $\varepsilon_{R}=0.04 \%$, as provided in [59]; for fatigue analysis, the target number of cycles to failure $N=$ 1000. By selecting several scale paths with different ratio between $P$ and $\Delta T$, a number of data points can be derived and plotted into a smooth curve. The convergence histories of the maximum equivalent ratchet strain and the minimum number of cycles to failure in the structure for three scale paths have been plotted in Fig. 16. Using the bisection scheme, the $\varepsilon_{R}$ and $N$ would converge rapidly in around 5 sub-cycles. For the same problem of determining the ratchet boundary for the holed plate subjected to load case I, another generalised method proposed in [19] takes about 10-15 sub-cycles before convergence criterion is met. Therefore, the bisection scheme used in this work is more computationally efficient and versatile for structural fatigue and ratchet analysis.

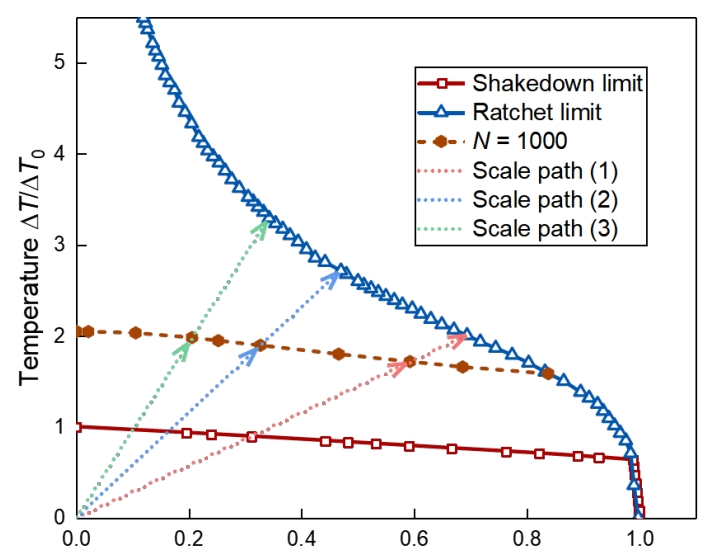

(a)

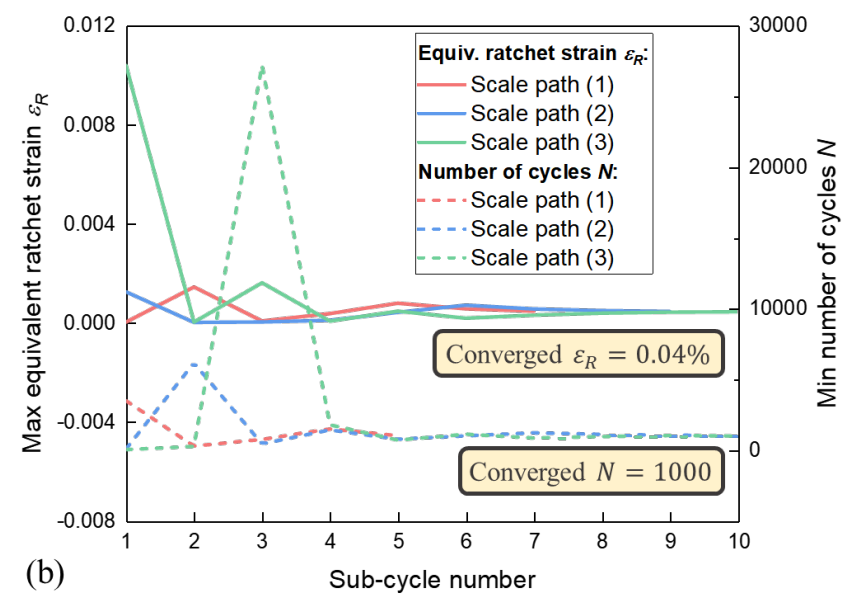

Fig. 16. (a) Three scale paths used to plot ratchet limit and constant fatigue life curves; (b) convergence histories of the maximum equivalent ratchet strain and the minimum number of cycles to failure for three scale paths.

The shakedown and ratchet boundaries for both load cases have been compared in Fig. 17(a). It can be observed that the shakedown boundaries intersect with both axes at the same point. However, 
the reverse plasticity limits are different due to the variation in the cyclic stress range. Compared to load case II, load case I results in a more augmented and less conservative ratchet limit because of the absence of the constant mechanical load. To verify the accuracy of the shakedown and ratchet limit for load case I, several load points have been selected for ABAQUS step-by-step analyses, as shown in Fig. 17(a). The evolution of the maximum plastic strain magnitude PEMAG of the holed plate for load points (3), (7) and (8) have been plotted in Fig. 17(b). The load point (3) is in the reverse plasticity region, and after a few cycles, the plastic strain ceases from increasing and begin fluctuating around a specific value. The load point (7) is in the shakedown region, and the structural behaviour is elastic after a few cycles with a constant plastic strain. The load point (8) is in the ratchet region, and the ratchet strain continuously grows larger for each cycle. Therefore, the evolution of plastic strain agrees well with the shakedown and ratchet boundaries, proving the accuracy of the UPFRA.
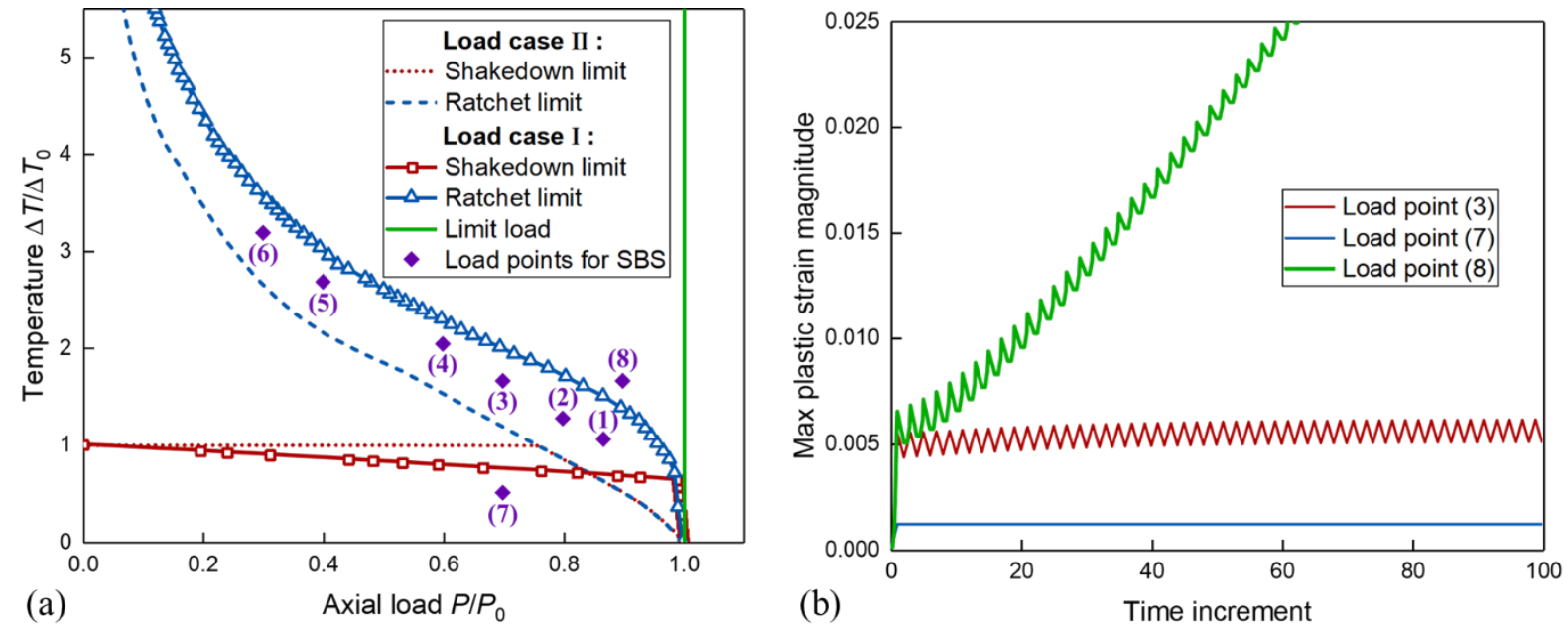

Fig. 17. (a) Comparison of boundaries of the holed plate subjected to two load cases, and load points considered for ABAQUS step-by-step analysis; (b) evolution of the maximum plastic strain magnitude of the holed plate obtained with ABAQUS step-by-step analysis.

Load point (3) is chosen from the constant fatigue life curve when the number of cycles to failure $N=1000$. Some DSCA contours have been extracted and shown in Fig. 18. The equivalent ratchet strain $\varepsilon_{R}$ in Fig. 18(a) predicts the failure mechanism of the holed plate: the structural would first fail at the inner hole and the upper-left edge, then the plastic zone would merge and expend until the holed 
plate is broken through in the vertical direction. The maximum $\varepsilon_{R}=0.01013 \%<0.04 \%$, so load point (3) has been proved to be located inside the ratchet boundary. The equivalent total strain range $\Delta \varepsilon_{t}$ in Fig. 18(b) shows the location of low cycle fatigue damage when the holed plate is subjected to load point (3). Large $\Delta \varepsilon_{P}$ can be found at the corner of the inner hole and at the upperleft edge. Using the bilinear interpolation technique and the fatigue curves of X2CrNiMo17-12-2 steel, the number of cycles to failure $N$ can then be calculated, as given in Fig. 18(c). The structural minimum $N=1000$, so load point (3) has been proven to be situated on the constant fatigue life curve of $N=1000$.

To further verify the accuracy of DSCA, a step-by-step analysis has been conducted for load point (3) with load case I applied. Some contours obtained with DSCA and SBS have been compared in Fig. 19. Comparing the contours of von Mises steady-state stress during loading and unloading stage, a similar stress distribution between DSCA and SBS can be observed, with some minor difference due to numerical errors. As mentioned in the previous example, the equivalent plastic strain range $\Delta \varepsilon_{P}$ is obtained by subtracting the equivalent plastic strain PEEQ at the step before the last step from the PEEQ at the last step for SBS. The distribution of $\Delta \varepsilon_{P}$ obtained with SBS and DSCA are nearly identical, as shown in Fig. 19(c) and Fig. 19(f). The largest $\Delta \varepsilon_{P}$ is found at the bottom edge of the inner hole. Therefore, an integration point in that region is chosen, with its steady-state stress-strain behaviour studied further.
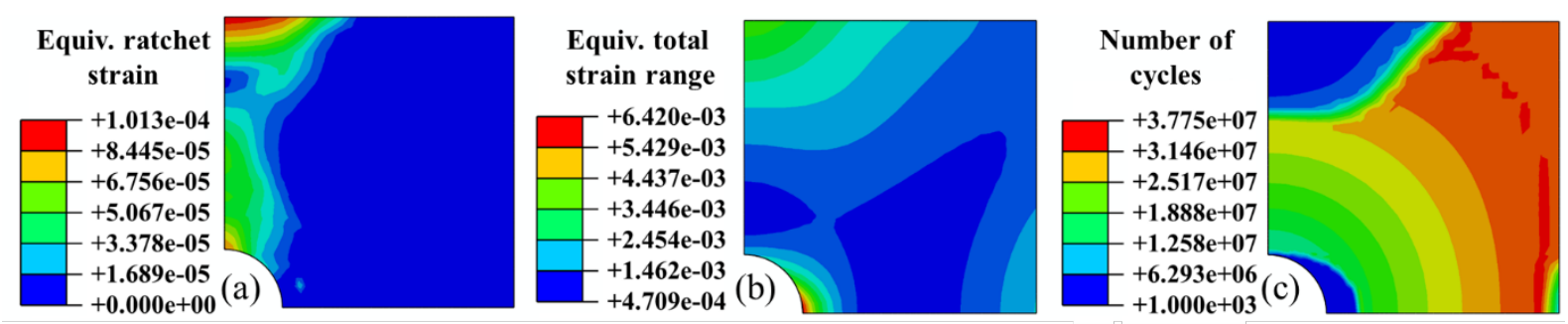

Fig. 18. DSCA contours for load point (3): (a) equivalent ratchet strain; (b) equivalent total strain range; (c) the number of cycles to failure. 

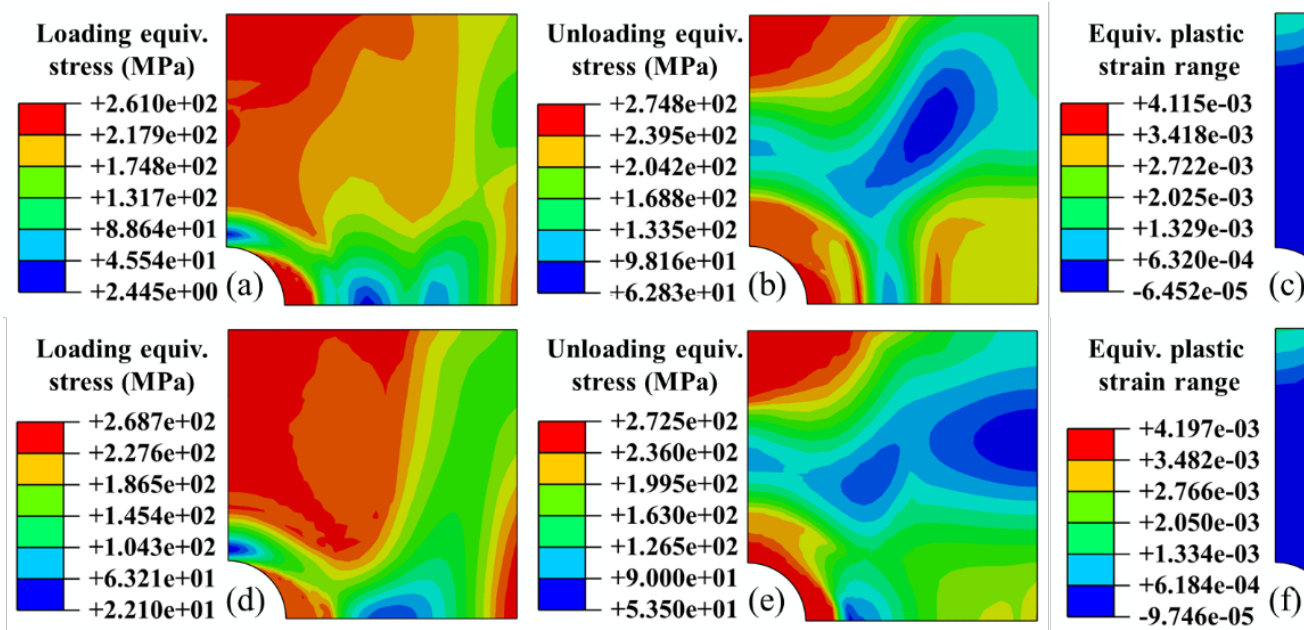

(c)
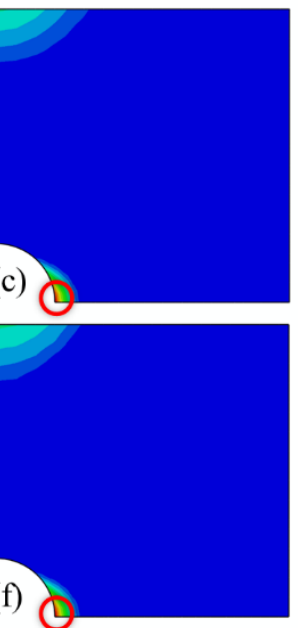

Fig. 19. Comparison of contours for load point (3): (a) von Mises steady-state stress during loading process obtained with DSCA; (b) von Mises steady-state stress during unloading process obtained with DSCA; (c) equivalent plastic strain range $\Delta \varepsilon_{P}$ obtained with DSCA and the location of maximum $\Delta \varepsilon_{P} ;$ (d) von Mises steady-state stress during loading process obtained with SBS; (e) von Mises steady-state stress during the unloading process obtained with SBS; (f) $\Delta \varepsilon_{P}$ obtained with SBS and the location of maximum $\Delta \varepsilon_{P}$.

The saturated hysteresis loops for the integration point highlighted in Fig. 19(c) and Fig. 19(f) obtained with LMM and SBS have been plotted in Fig. 20(a). The stress is bounded by the yield stress at the local temperature because of the Elastic Perfectly Plastic (EPP) model adopted. Due to the temperature dependency of material properties, the largest stress for each load points varies, depending on the yield stress at certain temperature $T$. The lowest stress for each load points are identical, which are equal to yield stress at $T=0$. Comparing load points (1)-(3), it can also be observed that strain range rises with increasing temperature and decreasing axial pressure, which means that for all three load points, the structural failure is dominant by the thermal load.

The comparison of maximum plastic strain range $\Delta \varepsilon_{p}$ obtained with LMM and SBS is presented in Fig. 20(b). It is worth noting that the strain range calculated by LMM is slightly smaller than the one calculated by SBS. The reason is that in LMM, the strain range is firstly computed by subtracting the strain tensors between loading and unloading stage, before calculating the equivalent strain range using the result tensors. While in SBS, the equivalent strains at loading and unloading stage are 
initially computed by ABAQUS, then subtracted to get the strain range values. Therefore, some numerical errors would occur using these two different processing strategies. For load points (1)-(6), the average difference of $\Delta \varepsilon_{p}$ between LMM and SBS is $2.96 \%$, proving the precision and robustness of the LMM and the UPFRA.
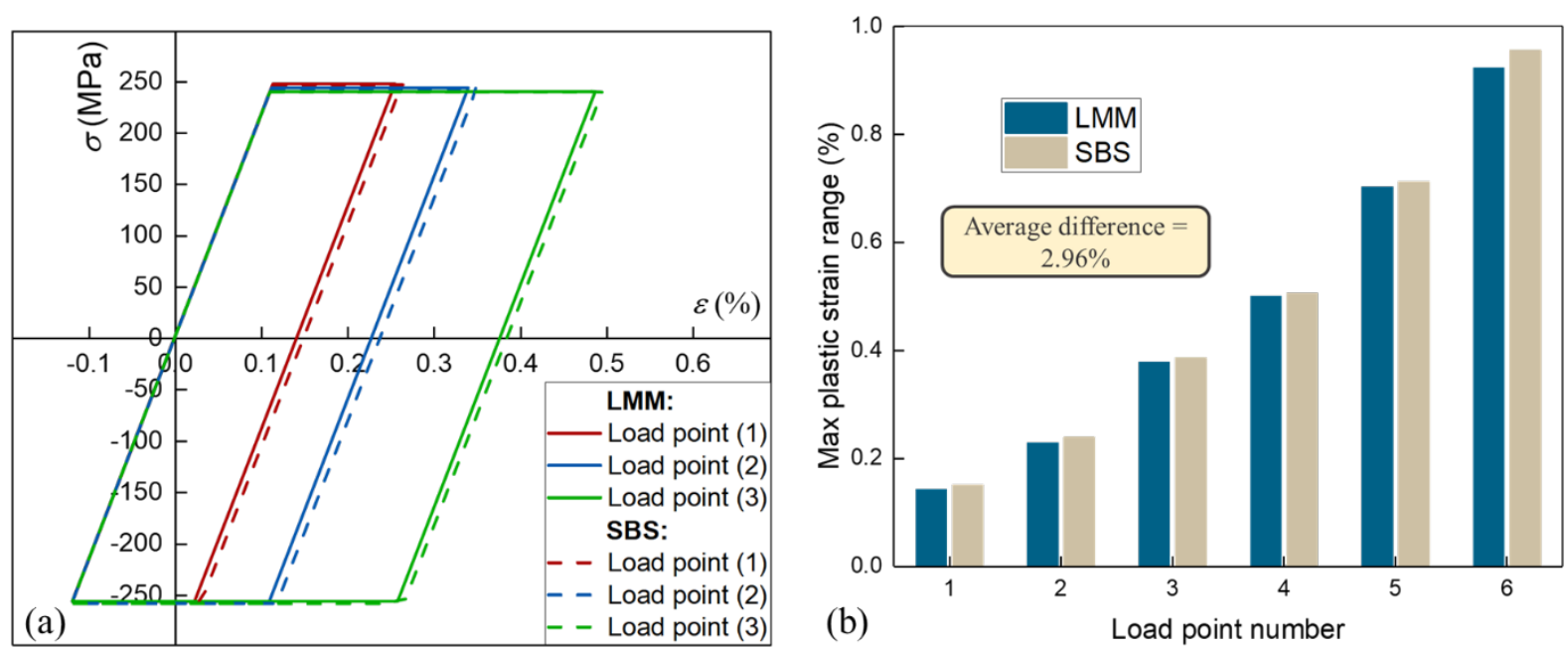

Fig. 20. Comparison of (a) saturated hysteresis loops obtained with LMM and SBS; (b) maximum plastic strain range obtained with LMM and SBS.

\section{Conclusions}

The concept of constant life diagram has been extended from material level to structure level. A Unified Procedure for Fatigue and Ratchet Analysis (UPFRA) has been proposed to generate the ratchet boundary and the LCF life boundary for components subjected to arbitrary cyclic thermalmechanical load histories. Case studies on two different engineering structures have been performed using the proposed numerical procedure. However, there are some limitations in the proposed procedure that can be further improved. It is widely acknowledged that material hardening may have a strong effect on the fatigue life of structures, leading to less-conservative LCF life boundaries. So for future work, the cyclic hardening effect of materials could be considered in the UPFRA using Ramberg-Osgood models. The main results and conclusions of this work are summarized as follows: 
(1) Material ratchetting is activated by non-zero mean stress or a zero mean stress with tensioncompression asymmetry and is considered in a homogeneous cyclic stress field with no residual stress involved; while structural ratchetting is considered in an inhomogeneous cyclic stress field with residual stress involved and can be demonstrated by an Elastic Perfectly Plastic (EPP) model for conservatism and simplification.

(2) For Bree-like problems, a two-stage procedure is introduced which is comprised of the Direct Steady Cycle Analysis (DSCA) algorithm and the Koiter's shakedown theorem; while for engineering problems with arbitrary cyclic loads involved, a three-stage procedure is proposed which is composed of the shakedown analysis and the UPFRA.

(3) By iteratively calling the DSCA subroutine controlled by a bisection scheme, the UPFRA has been successfully employed in various engineering problems considering complex geometry and temperature-dependent material properties with high computational efficiency.

(4) A series of data points have been chosen for verification with the ABAQUS step-by-step (SBS) analysis. The steady-state stress contours, the equivalent plastic strain range contours and the saturated hysteresis loops have been plotted, which agreed well with the results obtained with the LMM DSCA module, proving the accuracy of the ratchet boundaries and the structural constant fatigue life curves obtained with the UPFRA.

(5) In terms of future work, the cyclic hardening effect of material could be considered

\section{Acknowledgements}

The authors gratefully acknowledge the supports from the National Natural Science Foundation of China (51828501), the Higher Education Discipline Innovation Project (111 Project) under the funding code B13020, University of Strathclyde, East China University of Science and Technology and Tsinghua University during the course of this work. 


\section{References}

[1] A. Toudehdehghan, T.W. Hong, A critical review and analysis of pressure vessel structures, in: IOP Conf. Ser.: Mater. Sci. Eng., IOP Publishing, 2019, pp. 012009.

[2] A.D. Patil, M.M. Jadhav, Analysis of Pressure Vessel: A Review, International Journal for Innovative Research in Science \& Technology, ISSN (online), 2349-6010.

[3] M. Khattak, A. Mukhtar, K.A. Khan, Common root causes of pressure vessel failures: a review, Advanced Research in Applied Mechanics, 21 (2016).

[4] Y.M. Hashemi, M. Kadkhodaei, M.R. Mohammadzadeh, Fatigue analysis of shape memory alloy helical springs, Int. J. Mech. Sci., 161 (2019) 105059.

[5] N. Moslemi, F. Mozafari, B. Abdi, S. Gohari, N. Redzuan, C. Burvill, A. Ayob, Uniaxial and biaxial ratcheting behavior of pressurized AISI 316L pipe under cyclic loading: Experiment and simulation, Int. J. Mech. Sci., (2020) 105693.

[6] H. Su, J. Li, Q. Lai, C.L. Pun, P. Mutton, Q. Kan, G. Kang, W. Yan, Ratcheting behaviour of flash butt welds in heat-treated hypereutectoid steel rails under uniaxial and biaxial cyclic loadings, Int. J. Mech. Sci., 176 (2020) 105539.

[7] K. Kolasangiani, K. Farhangdoost, M. Shariati, A. Varvani-Farahani, Ratcheting assessment of notched steel samples subjected to asymmetric loading cycles through coupled kinematic hardening-Neuber rules, Int. J. Mech. Sci., 144 (2018) 24-32.

[8] E. Santecchia, A. Hamouda, F. Musharavati, E. Zalnezhad, M. Cabibbo, M. El Mehtedi, S. Spigarelli, A review on fatigue life prediction methods for metals, Adv. Mater. Sci. Eng., 2016 (2016).

[9] H. Luo, G. Kang, Q. Kan, C. Ma, Experimental study on the whole - life heterogeneous ratchetting and ratchetting - fatigue interaction of SUS301L stainless steel butt - welded joint, Fatigue \& Fracture of Engineering Materials \& Structures, 43 (2020) 36-50.

[10] L. Portier, S. Calloch, D. Marquis, P. Geyer, Ratchetting under tension-torsion loadings: experiments and modelling, Int. J. Plast., 16 (2000) 303-335. 
[11] R. Halama, M. Fusek, Z. Poruba, Influence of mean stress and stress amplitude on uniaxial and biaxial ratcheting of ST52 steel and its prediction by the AbdelKarim-Ohno model, Int. J. Fatigue, 91 (2016) 313-321.

[12] J. Chaboche, D. Nouailhas, Constitutive modeling of ratchetting effects—part i: experimental facts and properties of the classical models, (1989).

[13] Q.H. Kan, J. Li, H. Jiang, G.Z. Kang, An Improved Thermo-Ratcheting Boundary of Pressure Pipeline, in: Key Eng. Mater., Trans Tech Publ, 2017, pp. 311-315.

[14] A. Ponter, M. Megahed, Creep and plastic ratchetting in cyclically thermally loaded structures, in: Physical Non-Linearities in Structural Analysis, Springer, 1981, pp. 220-227.

[15] P. Segle, G. Eklund, M. Skog, A two-rod testing approach for understanding ratcheting in structures, Int. J. Press. Vessels Pip., 139 (2016) 184-193.

[16] J. Bree, Elastic-plastic behaviour of thin tubes subjected to internal pressure and intermittent high-heat fluxes with application to fast-nuclear-reactor fuel elements, Journal of strain analysis, 2 (1967) 226-238.

[17] A. Boiler, P.V. Code, Section III, Division 1 - Subsections NB, NC, ND, NCA and Appendices, American Society of Mechanical Engineers, New York, (2001).

[18] R. Bradford, The Bree problem with primary load cycling in-phase with the secondary load, Int. J. Press. Vessels Pip., 99 (2012) 44-50.

[19] M. Lytwyn, H. Chen, A.R. Ponter, A generalised method for ratchet analysis of structures undergoing arbitrary thermo - mechanical load histories, Int. J. Numer. Methods Eng., 104 (2015) 104-124.

[20] B. Pommier, Détermination de la réponse asymptotique d'une structure anélastique soumise à un chargement thermomécanique cyclique, in, 2003.

[21] D. D'Angela, M. Ercolino, Finite element analysis of fatigue response of nickel steel compact tension samples using ABAQUS, Procedia Struct. Integrity, 13 (2018) 939-946. 
[22] B. Nečemer, J. Kramberger, S. Glodež, THE LCF-ANALYSES OF AUXETIC STRUCTURE USING DIRECT CYCLING ALGORITHM, in: InCell 2019: Book of Abstracts of the International Conference on Multifunctional Cellular Materials, UA Editora Universidade de Aveiro, 2019, pp. 65.

[23] W. Reinhardt, A noncyclic method for plastic shakedown analysis, J. Pressure Vessel Technol., 130 (2008).

[24] W. Reinhardt, R. Adibi-Asl, Lower Bound Methods in Elastic-Plastic Shakedown Analysis, J. Pressure Vessel Technol., 136 (2014).

[25] Y.-G. Zhang, An iteration algorithm for kinematic shakedown analysis, Computer methods in applied mechanics and engineering, 127 (1995) 217-226.

[26] E. Christiansen, K.D. Andersen, Computation of collapse states with von Mises type yield condition, Int. J. Numer. Methods Eng., 46 (1999) 1185-1202.

[27] J.-W. Simon, D. Weichert, Numerical lower bound shakedown analysis of engineering structures, Computer Methods in Applied Mechanics and Engineering, 200 (2011) 2828-2839. [28] Y. Liu, X. Zhang, Z. Cen, Lower bound shakedown analysis by the symmetric Galerkin boundary element method, Int. J. Plast., 21 (2005) 21-42.

[29] S. Chen, Y. Liu, Z. Cen, Lower bound shakedown analysis by using the element free Galerkin method and non-linear programming, Computer Methods in Applied Mechanics and Engineering, 197 (2008) 3911-3921.

[30] D. Marriott, Evaluation of deformation or load control of stresses under inelastic conditions using elastic finite element stress analysis, ASME PVP, 136 (1988) 3-9.

[31] R. Seshadri, Inelastic evaluation of mechanical and structural components using the generalized local stress strain method of analysis, Nucl. Eng. Des., 153 (1995) 287-303. [32] D. Mackenzie, J. Shi, J. Boyle, Finite element modelling for limit analysis by the elastic compensation method, Computers \& structures, 51 (1994) 403-410. 
[33] H. Chen, A.R. Ponter, Shakedown and limit analyses for 3-D structures using the linear matching method, Int. J. Press. Vessels Pip., 78 (2001) 443-451.

[34] H. Chen, A.R. Ponter, A method for the evaluation of a ratchet limit and the amplitude of plastic strain for bodies subjected to cyclic loading, European Journal of Mechanics-A/Solids, 20 (2001) 555-571.

[35] E. Melan, Ingenieur-Archiv, Zur Plastizität des räumlichen Kontinuums, 9 (1938) 116-126.

[36] W. Koiter, Progress in solid mechanics, vol, 6 (1960) 167-221.

[37] R. Seshadri, The generalized local stress strain (GLOSS) analysis - theory and applications, (1991).

[38] D. Mackenzie, J. Boyle, R. Hamilton, The elastic compensation method for limit and shakedown analysis: a review, The Journal of Strain Analysis for Engineering Design, 35 (2000) $171-188$.

[39] H. Peng, Y. Liu, H. Chen, A numerical formulation and algorithm for limit and shakedown analysis of large-scale elastoplastic structures, Comput. Mech., 63 (2019) 1-22.

[40] H. Peng, Y. Liu, H. Chen, J. Shen, Shakedown analysis of engineering structures under multiple variable mechanical and thermal loads using the stress compensation method, Int. J. Mech. Sci., 140 (2018) 361-375.

[41] D. Barbera, H. Chen, Y. Liu, Review and Case Study of the Linear Matching Method Framework for Structure Integrity Assessment, in: ASME 2016 Pressure Vessels and Piping Conference, American Society of Mechanical Engineers Digital Collection, 2016.

[42] H. Chen, A.R. Ponter, A direct method on the evaluation of ratchet limit, J. Pressure Vessel Technol., 132 (2010).

[43] X. Zheng, H. Chen, Z. Ma, F. Xuan, A novel fatigue assessment approach by Direct Steady Cycle Analysis (DSCA) considering the temperature-dependent strain hardening effect, Int. J. Press. Vessels Pip., 170 (2019) 66-72. 
[44] P. Bayati, A. Jahadakbar, M. Barati, M. Nematollahi, L. Saint-Sulpice, M. Haghshenas, S.A.

Chirani, M.J. Mahtabi, M. Elahinia, Toward low and high cycle fatigue behavior of SLM-fabricated

NiTi: considering the effect of build orientation and employing a self-heating approach, Int. J.

Mech. Sci., (2020) 105878.

[45] F. Mozafari, P. Thamburaja, A. Srinivasa, N. Moslemi, A rate independent inelasticity model with smooth transition for unifying low-cycle to high-cycle fatigue life prediction, Int. J. Mech. Sci., 159 (2019) 325-335.

[46] C. Sonsino, Fatigue design for powder metallurgy, Powder Metall., 33 (1990) 235-245.

[47] A. Wöhler, Versucheüber die festiykeit eisenbahnwagenuchsen, Z Bauwesen, 10 (1860).

[48] L.F. Coffin Jr, A study of the effects of cyclic thermal stresses on a ductile metal, Transactions of the American Society of Mechanical Engineers, New York, 76 (1954) 931-950.

[49] S.S. Manson, Behavior of materials under conditions of thermal stress, National Advisory Committee for Aeronautics, 1953.

[50] G. Sendeckyj, Constant life diagrams - a historical review, Int. J. Fatigue, 23 (2001) 347-353.

[51] A. Sarkar, A. Nagesha, R. Sandhya, M. Mathew, Generation of constant life diagram under elevated temperature ratcheting of 316LN stainless steel, High Temp. Mater. Processes (London), 35 (2016) 361-368.

[52] T. Topper, R. Wetzel, J. Morrow, Neuber's rule applied to fatigue of notched specimens, in, Illinois univ at Urbana dept of theoretical and applied mechanics, 1967.

[53] D. Kujawski, J.L. Teo, A generalization of Neuber's rule for numerical applications, Procedia Struct. Integrity, 5 (2017) 883-888.

[54] D.W. Spring, E. Gassama, A. Stenta, J. Cochran, C. Panzarella, On the Applicability of Neuber's Rule for Low-Cycle Fatigue, in: Pressure Vessels and Piping Conference, American Society of Mechanical Engineers, 2016, pp. V01BT01A062.

[55] H. Neuber, Theory of stress concentration for shear-strained prismatical bodies with arbitrary nonlinear stress-strain law, (1961). 
[56] G. Glinka, Energy density approach to calculation of inelastic strain-stress near notches and cracks, Eng. Fract. Mech., 22 (1985) 485-508.

[57] A. Boiler, P.V. Code, Section VIII, Division 2: Alternative rules, rules for construction of pressure vessels, in, American Society of Mechanical Engineers, New York, 2007.

[58] D. Barbera, H. Chen, Y. Liu, F. Xuan, Recent developments of the linear matching method framework for structural integrity assessment, J. Pressure Vessel Technol., 139 (2017).

[59] M. Lytwyn, H. Chen, M. Martin, Ratchet analysis of structures under a generalised cyclic load history, in: ASME 2014 Pressure Vessels and Piping Conference, American Society of Mechanical Engineers Digital Collection, 2014.

[60] A.R. Ponter, H. Chen, A minimum theorem for cyclic load in excess of shakedown, with application to the evaluation of a ratchet limit, European Journal of Mechanics-A/Solids, 20 (2001) $539-553$.

[61] R.K. Agarwal, Recent Progress in Some Aircraft Technologies, BoD-Books on Demand, 2016.

[62] D. Hibbitt, B. Karlsson, P. Sorensen, Abaqus 6.12. 3 Manual, Dassault Systèmes Simulia Corp., Providence, RI, (2012).

[63] H. Chen, Lower and upper bound shakedown analysis of structures with temperaturedependent yield stress, J. Pressure Vessel Technol., 132 (2010) 011202.

[64] H. Chen, A.R. Ponter, Integrity assessment of a 3D tubeplate using the linear matching method. Part 1. Shakedown, reverse plasticity and ratchetting, Int. J. Press. Vessels Pip., 82 (2005) 85-94.

[65] H. Chen, A.R. Ponter, Integrity assessment of a 3D tubeplate using the linear matching method. Part 2: Creep relaxation and reverse plasticity, Int. J. Press. Vessels Pip., 82 (2005) 95-104. [66] C. RCC-MRx, Design and Construction rules for Nuclear Power Generating Stations, AFCEN, France, (2015). 